DOT/FAA/AM-01/2

Office of Aviation Medicine

Washington, D.C. 20591

\section{Access-to-Egress: A Meta-Analysis Of the Factors That Control Emergency Evacuation Through The Transport Airplane Type-III Overwing Exit}

\author{
Garnet A. McLean \\ Civil Aeromedical Institute \\ Federal Aviation Administration \\ Oklahoma City, Oklahoma 73125
}

January 2001

Final Report

This document is available to the public through the National Technical Information Service, Springfield, Virginia 22161.

U.S. Department of Transportation

Federal Aviation Administration 


\section{NOTICE}

This document is disseminated under the sponsorship of the U.S. Department of Transportation in the interest of information exchange. The United States Government assumes no liability for the contents thereof. 
Technical Report Documentation Page

\begin{tabular}{|c|c|c|c|c|}
\hline $\begin{array}{l}\text { 1. Report No. } \\
\text { DOT/FAA/AM-01/2 }\end{array}$ & \multicolumn{2}{|c|}{ 2. Government Accession No. } & \multicolumn{2}{|c|}{ 3. Recipient's Catalog No. } \\
\hline \multirow{2}{*}{\multicolumn{3}{|c|}{$\begin{array}{l}\text { 4. Title and Subtitle } \\
\text { Access-To-Egress: A Meta-Analysis of the Factors That Control } \\
\text { Emergency Evacuation Through the Transport Airplane Type-III } \\
\text { Overwing Exit }\end{array}$}} & \multicolumn{2}{|c|}{$\begin{array}{l}\text { 5. Report Date } \\
\text { January } 2001\end{array}$} \\
\hline & & & \multicolumn{2}{|c|}{ 6. Performing Organization Code } \\
\hline \multicolumn{3}{|l|}{ 7. Author(s) } & \multicolumn{2}{|c|}{ 8. Performing Organization Report No. } \\
\hline \multicolumn{5}{|l|}{ McLean, Garnet A. } \\
\hline \multirow{3}{*}{\multicolumn{3}{|c|}{$\begin{array}{l}\text { 9. Performing Organization Name and Address } \\
\text { FAA Civil Aeromedical Institute } \\
\text { P.O. Box } 25082 \\
\text { Oklahoma City, Oklahoma } 73125\end{array}$}} & \multicolumn{2}{|c|}{ 10. Work Unit No. (TRAIS) } \\
\hline & & & & \\
\hline & & & \multicolumn{2}{|c|}{ 11. Contract or Grant No. } \\
\hline \multirow{3}{*}{\multicolumn{3}{|c|}{$\begin{array}{l}\text { 12. Sponsoring Agency name and Address } \\
\text { Office of Aviation Medicine } \\
\text { Federal Aviation Administration } \\
800 \text { Independence Ave., S.W. } \\
\text { Washington, D.C. } 20591\end{array}$}} & \multicolumn{2}{|c|}{ 13. Type of Report and Period Covered } \\
\hline & & & & \\
\hline & & & 14. Sponsoring & \\
\hline \multicolumn{2}{|c|}{ This work was performed under task AM-B-00-PRS-93. } & & & \\
\hline \multicolumn{5}{|c|}{ 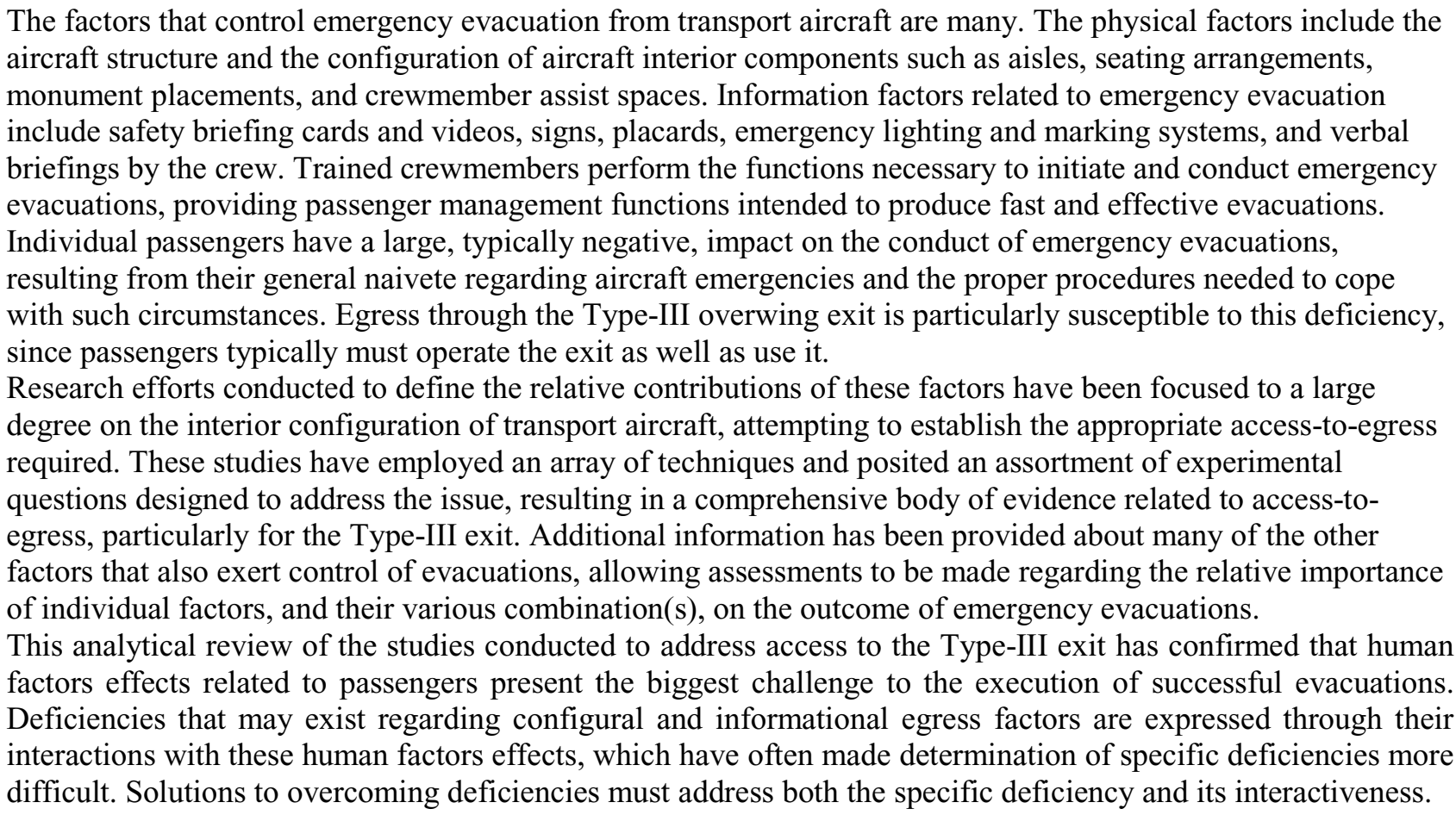 } \\
\hline \multicolumn{2}{|c|}{$\begin{array}{l}\text { 17. Key Words } \\
\text { Aircraft Evacuation, Passageway Configuration, Human } \\
\text { Factors, Hatch Operation, Competitive Behavior }\end{array}$} & \multicolumn{3}{|c|}{$\begin{array}{l}\text { 18. Distribution Statement } \\
\text { Document is available to the public through the } \\
\text { National Technical Information Service } \\
\text { Springfield, Virginia } 22161\end{array}$} \\
\hline $\begin{array}{l}\text { 19. Security Classif. (of this report) } \\
\text { Unclassified }\end{array}$ & $\begin{array}{r}\text { Security Classif. (of this pag } \\
\text { Unclassifi }\end{array}$ & & $\begin{array}{c}\text { No. of Pages } \\
31\end{array}$ & 22. Price \\
\hline
\end{tabular}

Form DOT F 1700.7 (8-72)

Reproduction of completed page authorized 



\section{Access-to-Egress: A Meta-Analysis of the Factors That Control Emergency Evacuation Through the Transport Airplane Type-III Overwing Exit}

\section{Theoretical Foundations}

It is well noted that accidents are generally the result of situations that a given system is not able to handle. Such is often the case for transport airplanes, where emergency situations can easily result in the need to hastily evacuate the airplane. Even with intact cabin interior configurations, these emergency situations can create interactive conditions that have not been fully predicted nor modeled.

Airplane configuration factors that have an effect on evacuations include exit size and availability, aisle width, seating arrangements, monument placement, and flight attendant assist space, as do such considerations as the number, ages, weights, gender, agility, health, and distribution of passengers and crew within the airplane. Loose carry-on baggage and galley carts, overhead bin displacements, and hull damage can provide additional impediments to egress. Problems increase dramatically when the environment becomes toxic from fire and smoke. Survival after some evacuations is also an issue that impacts the evacuation proper, as emergency provisions that may be needed in some environments must be transported as well. In sum, there is potentially no end to the complexity that an airplane accident might embody, and consequently, no end to the number or quality of interactions that can be imagined to exist in these scenarios.

Combined, the effects of potential interactions can appear unfailingly intertwined, unable to be teased apart successfully, and thus unable to be clearly understood in regard to the contributions of independent factors. These factors may also appear not to be testable or independently measurable without sacrificing the essence of the evacuation contingencies to be described. As a consequence, little validity may be attributed to the results obtained with the experimental tools and techniques used to date. Thus, the lack of absolute fidelity when experimentally simulating an emergency evacuation, in all its potential manifestations, may become an excuse to disregard data that do not conform to expectations.
The problem with such an ideological approach is that it is built on belief and assumption, not data, confounding science and technology with undefined contingencies and constraints. To quote Perrow (1999, pg. 63), "What is needed is an explanation based upon system characteristics." Without knowing or explaining the factors and the effects of those factors on an evacuation, the number or quality of possible interactions that those factors can effect is indeterminate (and perhaps greatly overestimated). Further, emergent (nested) factors that result from those interactions cannot be considered. Defining the system and its function(s), then, is a key concern.

In regard to interactions, it is again useful to turn to Perrow (1999, Ch. 3), who distinguishes between linear and complex interactions that result from the structure and function of linear and complex systems. Interestingly, Perrow (pg. 72) states, "Interactiveness per se, though, is not a useful concept." He makes this claim because "Almost any organization [system] of any size... will have many parts that interact... [which] is no great trouble for either system designers or system operators if their interactions are expected and obvious... These are linear interactions: production is carried out through a series or sequence of steps laid out in a line... It doesn't matter much whether there are 1,000 or $1,000,000$ parts... There will be product accumulating upstream and incomplete product going out downstream of the failure point." He also states, "Linear interactions overwhelmingly predominate in all systems" (pg. 75).

In contrast, complex interactions result from situations in which a single component is used to perform a common-mode function, resulting in "branching paths, feedback loops, jumps from one linear sequence to another... The connections are not only adjacent, serial ones, but can multiply as other parts or units or subsystems are reached... But even the most complex systems of any size will be primarily made up of linear, planned, visible interactions (pg 75)... Complex interactions are those of unfamiliar 
sequences, or unplanned or unexpected sequences, and [are] either not visible or not immediately comprehensible (pg. 78)."

However, "As we gain more experience with systems, and design them more effectively, the high degree of interactiveness may be reduced... It is also true that a poorly trained or inexperienced operator [observer] may see a system as replete with unsuspected interactions or 'traps', but after gaining more experience may find it to be more linear (pg. 84)... Limited knowledge, then, allows unsuspected interactions, and requires many control parameters and indirect sources of information (pg.85)." A corollary to this statement is the understanding that anyone who is unfamiliar with the intricacies of any system will find it more complex and less explainable. The number of factors will appear larger and more unmanageable, and their interactions can seem much more complicated.

From a research perspective, studying each factor in isolation would not clarify its effects on the function of the system as a whole, nor would it allow elucidation of its interaction(s) with other factors. However, studying as many contributing factors as possible, interwoven without regard for their individual contributions to the functioning of the system, would also provide little insight as to the importance of each factor and its interactive potential on total system function.

Instead, factorial studies implemented to illuminate the contributions to system function of an individual factor(s) and the interactions it produces with another factor(s) provide a basis for understanding the total system and its functions. "Factorial experimentation is highly efficient, because every observation supplies information about all the factors included in the experiment... [and] is a workmanlike method of investigating the relationships between the effects of different factors" (Snedecor \& Cochran, 1967, pg. 339). Further, "The factorial experiment allows the effects of each and every factor to be estimated and tested independently through the usual analysis of variance. In addition, the interaction effects are easily assessed. The disadvantage, of course, with the factorial experiment is the excessive amount of experimentation that is required" (Walpole \& Myers, 1972, pg.426). Combining the same factor with disparate factors in a series of small factorial experiments can overcome some of this need for excessive experimentation that a full factorial design requires, not to mention the positive benefits achieved regarding statistical analysis of smaller factorial datasets as compared with a large, multi-factorial database. Selection of appropriate factors to be addressed becomes the issue.

Thus, defining the experiment is the main consideration. First, the research design must be constructed to provide sufficient explanatory power (in terms of the research question being addressed). Toward this end, employing appropriate numbers of subjects/groups is important, as is designing the experiment to accurately reflect the levels of the factors being examined. Techniques of proper research design would include randomizing, matching, or blocking (so long as a replication of the experimental observations of the second factor(s) is accomplished for each block of the first) subjects assigned to experimental groups. Typically, this technique results in either complete between-subject research designs in which each subject/group receives only one level of each treatment, or randomized/counterbalanced within-subject research designs in which subjects are presented multiple treatment levels.

Secondly, measurement error must be minimized. Control of extraneous factors that could induce error is one such method for minimizing error. Factors to be controlled include those that have been shown to increase measurement error of a second factor, e.g., by being unstable during the course of an experiment. The effects of research subject experience and fatigue are examples of such instability. Randomizing or counterbalancing treatments to achieve unbiased presentation of factor levels is also necessary; both between-subject and within-subject research designs are treated thusly to mitigate against such effects, although each has its limitations. Germane to the issue at hand, purely between-subject research designs are extremely large and costly, while within-subject research designs are not appropriate for examining the effects of procedural treatments on subject performance. Thus, factorial experiments that can provide useful information must be constructed and controlled within a defined range of design constraints to yield maximal fidelity with regard to a limited number of identified factors.

In response, and as is typical of much research involving human subjects, targeted research questions are derived to address a subset of the total range of factors at work. Extraneous factors are controlled, where possible, to allow better discrimination of the other factors being studied. These factorial research designs are married with statistical techniques, such as analysis-of-variance, that provide the targeted answers 
being sought, including examination of the interactions that are obtained via the research design. This approach is theoretically opposed to more complex (uncontrolled) research that might be imagined to provide absolute fidelity regarding the entire range of (potential) contingencies evidenced in evacuations, but which would be very disorganized in practice, be extremely difficult to interpret regarding the responsibility of individual factors for specific effects seen, and not be certain to model the entire range of factors to be understood.

The final consideration, of course, is the degree to which the findings model reality. Failing the ability to make such comparisons, which is generally the case with regard to actual emergency evacuations, the findings must be compared with those from evacuation simulations employing similar techniques, as well as with results obtained using different methodologies. Should the effects of a studied factor not compare well with those from similar studies and techniques, then the measurement of the factor being addressed is suspect for one study or the other. However, should the effects compare well within one methodological approach but not with those from another, then the results may be technique-dependent, or perhaps an interaction is at work, and interpretation of the findings becomes potentially more problematic. There may be problems with both the validity and reliability of the results. If the results compare well both within and between methodological approaches, then they may be seen as more generalizable to the entire domain under study. This is an important consideration for the Type-III exit evacuation issues at hand.

\section{The Evacuation Problem}

The transport airplane, as an evacuation system, is generally designed to be linear. As such, when an incident/accident occurs, the crew assess external conditions; the crew open the exits to initiate the evacuation; the escape assist means are deployed (where provided); the crew direct the passengers to the emergency exits; the passengers and crew egress through the exits and onto the assist means; and the evacuation terminates in either a rescue or survival mode. While many airplane system elements participate to effect this process, each has been designed to perform dedicated functions that combine to produce the evacuation. A theoretical model of this process has been developed and described by the ARAC Performance Standards Working
Group within its Performance-Based Rulemaking for Transport Category Airplanes: A Systems Approach (1998).

Each element of the system and each step in the process may be thought of as a factor to be addressed in understanding the evacuation process. As a linear system, these factors are expected to exhibit linear interactions, if any, although the potential for complex interactions exists where common-mode functions are necessary. One such potential for interactions concerns the actions of the crew, who may be faced with the need to perform more than one (essentially simultaneous) activity. Where behavioral requirements overlap, the potential for either linear or complex interactions is evident, especially where passengers are also involved. Another potential common-mode function may be required of certain passengers, i.e., those who become responsible for operation of the (Type-III) exits. To the extent that the requirements for opening the exit influence the evacuation through that exit, additional interactions are possible. Generally, however, the potential for such interactions, whether linear or complex, is physically circumscribed to the area of the exit opening.

Within this context, airplane system elements contributing to an evacuation through the Type-III exit include physical, information, operator, and user factors. The seat assembly type; exit position and dimensions; exit plug weight; number, width, and arrangement of passageways; overhead bin configuration; and descent assisting means form the physical elements comprising the exit subsystem. Signs, placards, emergency lighting and marking systems, safety cards, and briefings (pre-flight and emergency-related) form the information subsystem elements. The crew (and some passengers) form the exit operator subsystem elements, and the passengers form the user subsystem of airplane system elements. Each airplane system element, outside of the passengers, is theoretically designed to achieve a specific effect with regard to producing a fast, effective evacuation. None of the elements is intended to rely on the functioning of other system elements, with the exception of the general need to have the Type-III exit operated by a passenger. This is the single potential interaction included by design, except for the necessary human factors effects related to passengers and crew navigating the passageway/exit/descent route.

The effects of other potentially interactive factors on the evacuation, especially those that exist at a distance from the exit, will be seen to be negligible, as long as 
the number of passengers prepared to egress through the Type-III exit is greater than the number that can be continuously accommodated, or unless the exit cannot accommodate the passengers available. For example, baggage in the aisle, overhead bin displacements, hull damage, etc., may affect the total airplane evacuation, but not necessarily egress through the (Type-III) exit. Similarly, toxic smoke and fire may impair the success of the evacuation, including egress through the Type-III exit, although the effects produced by the smoke and fire would not be seen to result from interactions with the physical airplane system elements, but by linear interactions with the passengers, and perhaps through derivative (complex) interactions mediated by effects on passenger perceptibility of information elements. Human factors effects, related to individual passenger differences in age, weight, agility, health, or psychological factors, may or may not be found to be interactive with the physical or information airplane system elements in an evacuation, depending on the degree to which any individual passenger impedes, or is impeded by, the egress of fellow passengers. Determining the degree to which any or all of these factors impact evacuations has been a main thrust of the empirical research to date.

\section{Evacuation Research}

The first FAA Office of Aviation Medicine Report on contingencies of evacuations was Evacuation Pattern Analysis of a Survivable Commercial Aircraft Crash (Hasbrook, Garner \& Snow, 1962). Subsequent to that report, Mohler, Swearingen, McFadden and Garner (1965) published Human Factors of Emergency Evacuations, which analyzed 49 incidents/accidents and 66 aircraft evacuation demonstrations to provide recommendations on 1) seating density, 2) aisle width, 3) exit number, size, and location, 4) exit markings, and 5) exit-opening strength requirements, as well as a number of human factors issues related to post-crash survival. The first published experimental investigation of factors related to evacuation of a crashed airplane occurred in 1964 (Garner and Blethrow, 1966). The factors of interest in that study were some of the same factors studied today: emergency lighting, exit signs, debris in the aisles, smoke effects on exit location, rescue of injured passengers, and egress with infants. Since that time dozens of additional investigations have been conducted on the importance of the physical, information, operational, and user factors related to egress in both incidents/accidents and simulations thereof - the result being that many data, especially human factors data, have been accumulated on the factors that influence evacuations. Knowledge derived from these studies, as well as information gained by airframe manufacturers and industry from their own studies, has been applied to the design of airplane (evacuation) systems, and much of this knowledge has been codified in the Code of Federal Regulations.

Building on the general state of knowledge about evacuation contingencies, more recent research has focused on the factors that impact evacuations through specific effects on passenger egress at floor-level and overwing exits. Included have been use of emergency lighting, exit size, type of descent assisting means, aircraft interior configuration, crewmember actions relative to egress, motivational state of passengers, and individual passenger attributes. Importantly, these studies have employed human research subjects, generating a comprehensive body of evidence about human performance in evacuations. Typically, these studies have also investigated the interactions of individual passenger attributes with the other factors being studied. In sum, much is known about human performance, its control, and its disruption, during both actual and simulated airplane emergencies and ensuing evacuations.

Evacuations through the Type-III exit have, within the last ten years or so, been particularly well-studied. Rasmussen and Chittum (1989) first described the effects of seating configuration adjacent to the Type-III exit on exit plug removal and egress, and that same year McLean, Higgins, Lyne, and Vant (1989) reported the effects of wearing protective breathing headgear (smokehoods) on evacuations through the Type-III and Type-IV exits in clear air and smoke. This work was complimented by that of Muir, Marrison, and Evans (1989), who evaluated passenger motivation on egress through different bulkhead apertures and different passageway configurations leading to a Type-III exit. Muir, Marrison, and Evans (1990) continued their studies, next assessing passageway-width effects in their "low" motivation condition and in smoke in a manner analogous to their 1989 work. Muir, Bottomley, and Hall (1992) again studied motivation effects on egress through bulkhead apertures and the Type-III exit in smoke, describing effects relative to different passageway widths. In parallel, McLean, Chittum, Funkhouser, Fairlie, and Folk (1992) reported the effects of dual or triple seat assembly placement next to either one or two Type-III exits on exit operation and speed of egress. 
Fennell and Muir (1993) next described the effects of exit plug weight and seat configuration on operation of the Type-III exit. McLean, George, Chittum, and Funkhouser (1995, Part I) conducted another study of seat placement effects on evacuations through the Type-III exit, designed specifically to compare a range of single passageway widths and aft seat assembly encroachment distances on egress. The data from this study were further examined by McLean and George (1995, Part II), highlighting the effects of individual passenger attributes and their interactions with the physical layout adjacent to the Type-III exit. Muir (1996) reported on another study of passageway configuration, looking specifically at narrow passageway widths. McLean, Corbett, and George (1999) later presented the results of an evacuation study examining the effects of passenger management (presence of a flight attendant at the Type-III exit) and passenger density in the cabin, and McLean and Corbett (2000) evaluated the effects of individual subject attributes in that study.

Combined, these studies enhance our general understanding of the human factors of egress from transport airplanes and identify the effects of many other specific factors and their interactions regarding egress through the Type-III exit. While the data are generally not amenable to direct statistical comparison because of differences in apparatus, methodologies, and possible cultural influences, there is an ability to determine whether the findings are mutually supportive and generally reliable and, by exclusion therefrom, whether any of the findings deserve not to be recognized.

\section{FINDINGS AND INTERPRETATIONS}

Rasmussen and Chittum (1989). The first study to address Type-III exit configuration issues was that of
Rasmussen and Chittum (1989). They compared four passageway configurations leading from the center aisle to the Type-III exit between triple seat assemblies: a) the then-current FAA minimum standard single passageway (6"- 8" with maximum aft seat encroachment into the exit opening), b) the CAA minimum single-passageway standard (10" with exit midline aft seat encroachment), c) the current FAA standard single passageway standard (20" with a 5" aft seat encroachment), and d) the current FAA standard dual passageway configuration with the outboard seat removed (OBR) and two 6" passageways (one fore and one aft of the exit). Four subject groups, ranging in age from 17 to 70 years, were employed. Presentation of the four passageway configurations was counterbalanced across the four groups, with exit plug removal times and egress flowrates through the Type-III exit being the dependent variables of interest.

Table 1 shows the flowrate results in a trial-by-trial format. One-way analysis of variance (ANOVA) found a significant main effect of passageway width on mean egress times; simple effects of individual passageway configurations were gauged by independent $t$-tests. The t-tests found that the dual 6" passageway configuration was significantly faster than both the 6" $(\mathrm{p}<.005)$, and 10 " $(\mathrm{p}<.01)$ single passageway configurations, and the 20 " single passageway configuration was significantly faster than the 6" single passageway configuration $(\mathrm{p}<.025)$, but not the 10 " single passageway configuration.

These were mean egress time data, obtained across a series of four trials, during which a significant degree of experience was being acquired by the subjects. For example, on the first egress trial when subjects were naïve, the 6 " single passageway configuration produced essentially identical egress times to the 20 " single-passageway. ANOVA showed no effects of passageway width on the first egress trial times; however, independent t-tests were then used to compare

TABLE 1

Individual Egress Times Through The Type-III Exit (Rasmussen and Chittum, 1989).

\begin{tabular}{|c|c|c|c|c|c|}
\hline \multirow{2}{*}{ Configuration } & \multicolumn{5}{|c|}{ Evacuation Trials } \\
\cline { 2 - 6 } & 1 & 2 & 3 & 4 & mean \\
\hline 6" single & $1.65 / 0.56$ & $1.81 / 1.03$ & $1.49 / 0.48$ & $1.53 / 0.64$ & $1.62 / 0.71$ \\
\hline $10 "$ single & $1.75 / 0.56$ & $1.41 / 0.39$ & $1.47 / 0.48$ & $1.44 / 0.56$ & $1.52 / 0.51$ \\
\hline 20" single & $1.67 / 0.71$ & $1.50 / 0.45$ & $1.29 / 0.33$ & $1.31 / 0.36$ & $1.44 / 0.50$ \\
\hline 6" dual OBR & $1.46 / 0.41$ & $1.38 / 0.32$ & $1.37 / 0.63$ & $1.28 / 0.37$ & $1.37 / 0.45$ \\
\hline
\end{tabular}


configurations. (Note that without a significant main effect in the ANOVA, this statistical approach is unwarranted.) Even so, the analysis showed that the 6" dual passageway configuration provided faster evacuations than the 10 " single passage-way $(\mathrm{p}<.01)$; no other differences were found on the first trial. Subsequent to that first trial, as can be seen in the table above, performance at each configuration varied significantly, eventually "sorting itself out" by the fourth trial, which mirrored the mean egress performance. Thus, as subjects acquired egress experience, eliminating the variability in their own individual performances, the effects on egress produced by passageway width, per se, were revealed.

A second phase of the study examined hatch (exit plug) removal times in a separate single-side cabin mockup, using three rows of seats configured identically to the passageway configurations employed in the flowrate trials. Forty active (exit opening) subjects, ranging in age from 19 to 58 years, were employed to prepare the Type-III exit for use. Additional passive subjects sat in the remaining seats. Each trial ended when the exit was available for egress. Note that in this phase of the study two different exit opening strategies were examined with the OBR (outboard seat removed) configuration. In the first case, the active subject sat in the middle seat adjacent to the exit; in the second case, the subject sat in the outboard seat aft of the exit.

The results from the exit preparation phase of the study can be found in Table 2 . The total exit preparation times were dissected to reveal the time to unlatch, and the time to dispose of, the exit plug. ANOVA failed to yield significant differences among the five configurations examined; nonetheless, independent t-tests were again employed to compare configurations. This analysis showed that the 6 " single passageway configuration allowed the exit plug to be unlatched faster that either the 20 " single passageway or the 6" OBR configuration with the subject seated adjacent to the exit, and the 10 " single passageway configuration also allowed the plug to be unlatched faster than the 6" OBR configuration with the subject seated adjacent to the exit. No differences were found among any of the configurations for either exit plug disposal time or total exit preparation time. These results indicate that, while small effects on exit plug removal may be produced by passageway configuration, these differences are embedded within a larger exit preparation process that is largely robust to perturbation by differences in passageway configuration.

In their discussion of the results, Rasmussen and Chittum (1989) noted that subjects with prior experience with the Type-III exit produced flowrate data of reduced variability, leading to increased statistical significance of the results obtained. As an example, they cited the egress time of a single subject using the 6 " single passageway configuration on trial 2 as being responsible for an $8.4 \%$ increase in mean egress time for that trial. The implication was that, as subjects learned to egress more effectively during the study, such deviant egress times were eliminated, illuminating specific effects of the passageway configurations. While generally true, removal of this particular outlying data point would have eliminated some of the average difference between the 6 " single passageway configuration and the faster 20" single and 6" OBR passageway configurations, conceivably eliminating the statistical significance of the passageway configuration effect.

Perhaps more importantly, their notation points to the fact that errant individual subject performance can skew results to suggest greater treatment effects than otherwise exist. Without specific knowledge about the particular reason for this data outlier, it is difficult

\section{TABLE 2}

Type-III Exit Preparation Times

(Rasmussen and Chittum, 1989).

\begin{tabular}{|c|c|c|c|c|c|}
\hline \multirow{2}{*}{$\begin{array}{c}\text { Exit } \\
\text { Opening } \\
\text { Activity }\end{array}$} & \begin{tabular}{c} 
P" Passageway Configuration \\
\cline { 2 - 6 }
\end{tabular} & $\begin{array}{c}\text { Single } \\
\text { S" OBR }\end{array}$ & $\begin{array}{c}\text { 6" OBR } \\
\text { (Aft) }\end{array}$ \\
\hline Unlatch Plug & $1.78 / 0.47$ & $2.08 / 0.41$ & $2.28 / 0.34$ & $2.54 / 0.60$ & $2.39 / 1.36$ \\
\hline Plug Disposal & $3.79 / 1.58$ & $3.55 / 1.75$ & $3.33 / 1.78$ & $3.68 / 1.36$ & $2.61 / 1.42$ \\
\hline Total Time & $5.56 / 1.95$ & $5.63 / 1.93$ & $5.60 / 1.74$ & $6.21 / 1.79$ & $5.00 / 2.33$ \\
\hline
\end{tabular}


to ascribe some systematic effect, human factors or otherwise, on egress performance. Further, without similar egress performance for this individual subject with the comparable 6" OBR configuration, it is unlikely that some unique personal interaction was at work. More globally, without similar egress performances by other (similar) subjects at all of the 6" passageway configurations, it is unlikely that a generalized human factors effect was responsible. Rather, the subject is apt to have made some misstep, such as slipping or getting a foot wedged between the outboard seat and the inside of the fuselage, that impaired his performance excessively on this single trial. Such instances happen often during evacuations and can obscure useful information relative to such questions as, "What is an appropriate passageway configuration?”

The authors also cited the uncontrolled placement of the exit plug as a factor relevant to their findings. Lacking specific instructions on exit plug disposal, subjects using the 6" dual passageway configuration evidenced more instances of leaning the plug against the inside of the fuselage beneath the exit opening, whereas trials at the narrower 6 " and 10" single-passageway configurations resulted in the subjects placing the plug vertically in the seat they had previously occupied or on the passageway floor. (No mention was made of what was done with the plug at the 20" passageway configuration.) In the first case, Rasmussen and Chittum (1989) concluded that the placement appeared not to offer the potential for significant impediments to egress, although they judged placement vertically in the unoccupied seat or placement on the passageway floor to have the potential for adverse effects. Lacking data to support their speculations, they suggested that additional studies would have to be conducted to assess the interaction effects of these potential exit plug placements and specific passageway configurations on evacuations.

Thus, the Rasmussen and Chittum (1989) study was able to determine the effects of several factors. First, the human factors effects, related to naïve subject performance, clearly outweighed the effects of passageway configuration and produced variable placement of the exit plug subsequent to its removal. Second, the passageway configuration, per se, was shown to produce systematic effects on evacuation times, these being evidenced as the human factors effects waned with increasing subject experience. Third, passageway configuration had little effect on time for preparation of the Type-III exit, although the lack of appropriate experimental controls, regarding placement of the exit plug after its removal, confounded the ability to accurately describe any systematic potential for an interaction between passageway configuration and exit plug placement. Together, these findings support an initial understanding that while the factors involved in evacuations through the Type-III exit may seem exceedingly complex and inestimably intermingled, careful examination through wellcontrolled factorial research studies has the potential to illuminate the individual and combined contributions that specific egress factors provide.

McLean, Chittum, Funkhouser, Fairlie, and Folk (1989). Another study relevant to these issues was that of McLean et al. (1989), in which the effects of wearing smokehoods on evacuations through Type-III (20" x 36 ") and Type-IV (19" x 26") exits in clear air and smoke were examined. Access to the exits conformed to the then-typical minimum single-passageway width of 6 inches. The theatrical smoke was maintained during egress trials at an optical density of approximately 0.5 per foot, i.e., the density at which human survival in a transport airplane fire is possible for approximately 90 to 120 seconds (cf. Crane, 1978).

Subjects ranged in age from 18-63 years. Each subject group performed two egress trials, which were counterbalanced regarding the wearing of smokehoods versus not. The hoods were of two sizes. The first was small and hugged the subjects' heads rather closely, while the second was much larger and "ballooned" when activated. Both total evacuation times and individual "hatch-crossing times" were examined.

In Phase 1 of the study, the evacuations without smokehoods in clear air through the Type-III exit were faster than those through the Type-IV exit $(\mathrm{p}<.005)$, and wearing smokehoods increased egress times through both exit types $(\mathrm{p}<.05)$. The effects of smoke were found to depend on the obscuration of visual information in the area of the exit opening, as opposed to delaying approach to the exit. As can be seen in Table 3, the exit size effect was much larger than the effect of wearing smokehoods. As is typical, smoke in the cabin slowed evacuations through the Type-III exit significantly when compared with clear air. However, egress through the Type-IV exit did not conform to this effect, probably because exit size was a much more powerful factor. Individual hatch crossing times accounted for the significant main effects of both exit opening size and wearing of smokehoods; the larger smokehood also produced longer hatch crossing times than did the 


\section{TABLE 3}

Individual Hatch Crossing Times

(McLean et al., 1989)

\begin{tabular}{|c|c|c|c|c|}
\hline & \multicolumn{2}{|c|}{ Clear Air } & \multicolumn{2}{c|}{ Smoke } \\
\cline { 2 - 5 } & Type III & Type IV & Type III & Type IV \\
\hline PPBE & $1.70 / 0.12$ & $3.30 / 0.15$ & $2.00 / 0.09$ & $3.30 / 0.16$ \\
\hline No PPBE & $1.40 / 0.08$ & $2.90 / 0.16$ & $1.70 / 0.08$ & $2.60 / 0.12$ \\
\hline
\end{tabular}

Times in seconds $=$ mean $/$ std err. $\quad n=20$ per group in clear air $/ 80$ per group in smoke

smaller one. The counterbalanced presentation of egress with/without a smokehood revealed an interaction effect whereby the increase in hatch crossing times produced by wearing smokehoods could be overcome by prior experience, but only in the clear air condition, affirming that obscuration of visual cues was the mechanism responsible for the increase in egress times seen.

In their discussion of the results, McLean et al. (1989) invoked the term "personal ergonomic workspace" to interpret the findings regarding slower egress performance at the smaller exit opening size and while using the larger smokehood. In both cases, as personal ergonomic workspace requirements increased, egress times increased as well. However, the finding that subject egress experience only eliminated smokehood effects in clear air indicates that visual psychomotor learning, not "skill practice" effects, was responsible for the effects of experience. This finding comports well with the findings of McLean and George (1995, Part II), in which older subjects were found to improve egress performance on a second egress trial at narrow passageway widths after many other egress trials at larger passageway widths, and after generalized egress skill through a Type-III exit opening was well established. Those authors (1995, Part II) concluded that a change in an individual subject's egress "strategy" was responsible. This 1989 finding was, therefore, another early indication that human factors effects predominate in the control of naïve subject performance in evacuations through the Type-III exit.

Muir, Marrison, and Evans (1989). The third relevant study was that of Muir et al. (1989), who studied subject flowrates between bulkheads and the effects of passageway width on egress through a Type-III exit. Focusing here on the Type-III exit phase of the study, the passageway configurations employed were 3", 13", 18", 25", and 34" single passageways between triple-seat assemblies and a 6" OBR dual-passageway configuration. Differences in the single-passageway configurations were achieved by locating the seat assembly forward of the exit as far rearward as possible for all of the passageway widths employed and moving only the seat assembly aft of the exit to get the desired passageway width. The 6" OBR configuration conformed to CAA Airworthiness Notice No. 79. For the 3"(a) single passageway configuration the outboard seat in the exit row had its recline and breakover restricted; in all other trials, all three of the exit row seatbacks were restricted in their ability to recline and breakover, assuring that the configuration was maintained along the entire length of the passageway. A total of 2262 subjects ( 60 per group), ranging in age from 20-50 years, was employed. Subject motivation level was a second factor of interest; a monetary bonus was offered to half of the subject groups, using a payoff strategy in which the first $50 \%$ of the subjects to evacuate in each group would receive a 5-pound bonus (half the participation fee) immediately upon exiting the airplane. Two competitive trials were conducted at each configuration, and subjects in the competitive groups performed four evacuations (two through the bulkhead and two through the Type-III exit), whereas non-competitive subjects performed two evacuations (one through the bulkhead and one through the Type-III exit). Trials were run in clear air.

The mean cumulative times for the first 30 subjects to evacuate through the Type-III exit in both the competitive and non-competitive evacuation trials can be found in Table 4. Also shown are the cumulative times for the 30 subjects to evacuate in the first and second trials in the competitive condition alone. Note the rather large, but statistically insignificant, variability between the times for the first and second egress trials at the various passageway configurations. ANOVA found a significant main effect of motivation condition $(\mathrm{p}<.001)$ on egress times, resulting from congestion at the exit associated with the competitive evacuations, 
TABLE 4

Total Cumulative Evacuation Times For the First 30 Subjects to Evacuate

(Muir et al., 1989)

\begin{tabular}{|c|c|c|c|c|}
\hline \multirow{2}{*}{$\begin{array}{c}\text { Passageway } \\
\text { Configuration }\end{array}$} & \multicolumn{3}{|c|}{ Competitive Trials } & Non-Competitive Trials \\
\cline { 2 - 5 } & $1^{\text {st }}$ trial & $2^{\text {nd }}$ trial & Mean & Mean \\
\hline 3"a & $83.8 / 11.2$ & $84.0 / 0.0$ & $83.9^{*} / 9.7$ & \\
\hline 3"b & $61.9 / 4.6$ & $81.0 / 17.0$ & $71.4^{*} / 15.0$ & $53.2 / 1.8$ \\
\hline 6" OBR & $55.1 / 11.6$ & $48.6 / 1.4$ & $53.2 / 10.0$ & $39.6 / 2.5$ \\
\hline $13 "$ & $54.6 / 13.4$ & $57.5 / 6.3$ & $55.9 / 10.3$ & $39.9 / 3.3$ \\
\hline 18" & $49.1 / 6.5$ & $58.5 / 7.7$ & $53.7 / 8.20$ & $37.2 / 0.2$ \\
\hline 25" & $54.9 / 14.3$ & $54.9 / 10.0$ & $54.9 / 11.5$ & $40.8 / 2.7$ \\
\hline $34 "$ & $57.2 / 5.7$ & $67.3 / 7.2$ & $62.3 / 8.10$ & $35.3 / 0.6$ \\
\hline
\end{tabular}

Times in seconds $=$ mean $/$ std. dev. $\quad$ * $=$ significant $(p<.05)$

which increased evacuation times. In fact, five of the competitive evacuation trials (two with the 3"(a) single passageway, two with the 6" single passageway, and one with the 18 " single passageway) had to be aborted because of blockages at the exit proper. Significant differences in mean egress times were also shown to result from the different passageway configurations in both the competitive $(\mathrm{p}<.001)$ and non-competitive $(\mathrm{p}<.01)$ conditions. However, no interaction effect of motivation condition with specific passageway configuration was reported, although mean times for the 3", 13", and 34" single passageway configurations were significantly different between competitive and non-competitive evacuations, while those for the 18 " and 25 " passageways were not.

The reason for the significant motivation-related differences at the 13" single-passageway configuration is unclear, given the smaller differences in its mean evacuation times, and the larger standard deviations associated with those times, when compared with times for the 18" single passageway configuration, which failed to achieve statistical significance. One likely explanation would be the aborted trial for the 18 " passageway, which would reduce the amount of data and the degrees of freedom in the analysis, thereby reducing its power.

A significant main effect of age $(\mathrm{p}<.0001)$ was shown in the competitive evacuation trials, as subjects over 35 years of age were generally in the latter positions in the evacuation stream. Gender effects were also highly significant in the competitive evacuation trials $(\mathrm{p}<.0001)$, males being much faster to egress. Finally, subjects who reported having an evacuation plan were more likely to receive a bonus in the competitive evacuation trials $(\mathrm{p}<.0001)$, and subjects who were able to use the aisle/passageway, instead of climbing over seatbacks to get to the Type-III exit, also had shorter evacuation times $(\mathrm{p}<.001)$. These effects were not found in the non-competitive condition.

Various competitive group subjects also were said to have walked over each other, searched for family and friends before attempting to egress, and had difficulty opening their seat belts; some subjects were even unable to move from their seats. A qualitative analysis of the videos from the evacuation trials led the authors to suggest that non-competitive evacuations 
were particularly useful in simulating precautionary evacuations and other evacuation events in which the physical conditions in the cabin have not deteriorated, whereas the use of monetary incentives has the potential to provide data more relevant to emergencies perceived as life-threatening. This interpretation was supported by accounts of survivors of an actual accident, which became progressively more involved with smoke and fire, and which had begun with orderly egress that evolved to resemble the competitive egress trials.

Citing the relative youth and good health of their subjects, Muir et al. (1989) suggested that evacuation times should be longer and [ergonomic] problems should be greater in the aftermath of an actual accident. They also suggested that exploration of a possible interaction between passageway configuration and exit plug removal/disposal would require crowding and pushing by subjects at the exit during the time the exit plug was being manipulated.

Thus, Muir et al. (1989) again confirmed large human factors effects on egress, including effects of subject motivation, strategic planning, age, and gender, as well as an array of behaviors both related and unrelated to egress. However, the positive effects of egress experience were not seen for the competitive evacuations, as the second trial was generally slower than the first trial. Comparisons of the effects of egress experience could not be made within the noncompetitive group results, or between the competitive and non-competitive group results, because of the lack of repeated egress trials for the non-competitive subjects. Given the strategy of paying the monetary bonus to, and reporting on, only the first $50 \%$ of subjects to egress in the competitive evacuations, the effects of the behavioral aberrations (searching for family, difficulties with seatbelt buckles, not moving from seats, etc.) in producing the competitive results are likely to be minimal. What is clear is that the high degree of subject motivation, especially at very narrow passageway widths, led to the exit blockages.

An effect of passageway configuration on speed of non-competitive egress was also replicated for the 3 " and 34" single-passageway configurations. ((Recall that these configurations were different from those of Rasmussen and Chittum (1989), who only compared $6 ", 10 "$, and 20 " passageway configurations)). The failure to find differences in flowrates for the 13", 18 ", and 25 " single-passageway configurations in both competitive and non-competitive evacuations suggested that these configurations were not ergonomically different from each other, although the authors surmised that the 18" passageway configuration could be optimum (in spite of the blockage at that passageway configuration in one competitive evacuation). These findings added weight to the interpretation that passageway configuration has a systematic influence on speed of egress, although the human factors aspects of evacuations were again shown to be a more important factor to be understood.

Muir, Marrison, and Evans (1990). The preceding (non-competitive) methodological approach was continued by Muir et al. (1990), who investigated the effects of theatrical smoke in the cabin on evacuations using four passageway configurations identical to those employed in their 1989 study. The configurations again included the 13", 18", and the 34" single passageways, as well as the 6" OBR dual passageway configuration. A total of 254 subjects, ranging in age from 20 to 50 years, and grouped 30 to 35 subjects per group, was employed. The optical density of the theatrical smoke was again maintained at approximately 0.5 per foot.

Table 5 presents the results of this study in comparison with the results from the Muir et al. (1989) study. ANOVA revealed no significant differences among configuration-based egress times in theatrical smoke, although comparison of the evacuations in smoke with the competitive and non-competitive evacuations conducted in 1989 showed a significant $(\mathrm{p}<.01)$ difference between the non-competitive evacuation times in clear air (1989) and those in smoke (1990), which were not significantly different from the (1989) competitive evacuation times. Interestingly, the 6" OBR configuration produced evacuations in smoke about six seconds slower than those in the competitive condition, whereas the evacuations in smoke with the $13 ", 18$ ", and 34" single- passageway configurations were about four seconds faster than were competitive evacuations in clear air for the same passageway configurations. The statistical significance of this apparent interaction effect was not reported, nor were any other interactions apparent in the reported results. The differences in research design between the two studies (number of evacuations per subject and number of subjects per group) makes clear-cut interpretation difficult.

Muir et al. (1990) suggested that removal of the outboard seat may have eliminated tactile cues that subjects would have used to aid their egress and recommended that additional evacuation studies be 


\section{TABLE 5}

Total Cumulative Mean Evacuation Times For The First 30 Subjects To Evacuate

(Muir et al., 1990)

\begin{tabular}{|c|c|c|c|}
\hline $\begin{array}{c}\text { Passageway } \\
\text { Configuration }\end{array}$ & $\begin{array}{c}\text { Competitive } \\
\text { Trials }\end{array}$ & $\begin{array}{c}\text { Non-Competitive } \\
\text { Trials }\end{array}$ & $\begin{array}{c}\text { Smoke } \\
\text { Trials }\end{array}$ \\
\hline 6" OBR & $53.2 / 10.0$ & $39.6 / 2.5$ & $59.6 / 9.9$ \\
\hline $13 "$ & $55.9 / 10.3$ & $39.9 / 3.3$ & $51.6 / 14.9$ \\
\hline $18 "$ & $53.7 / 8.20$ & $37.2 / 0.2$ & $49.6 / 7.0$ \\
\hline $34 "$ & $62.3 / 8.10$ & $35.3 / 0.6$ & $57.9 / 3.2$ \\
\hline
\end{tabular}

Times in seconds $=$ mean $/$ std. dev.

conducted to confirm the effect and its cause(s). They also recommended additional studies to determine the influence of seating configuration on ease of exit opening and placement of the exit plug in a smoke-filled cabin situation, as well as the interaction of theatrical smoke and egress competition.

Thus, this study extended our understanding of the effects of smoke on egress, as well as its relationship to the effects of passenger motivation and passageway configuration. However, because of the preliminary nature of the study, little information was made available regarding human factors effects and their potential for interactions with the effects of the independent treatments. Nonetheless, the lack of visual information, in general, was assuredly responsible for the generalized slowing of the evacuations in smoke, and the combination of minimal tactile cues and higher subject density at the exit, proper, was likely responsible for the additional slowing seen in the 6" OBR configuration. These effects were again relatively consistent with regard to the 13 " and 18 " single passageway configurations, indicating that no specific interaction of passageway configuration and smoke was producing discriminative differences in egress for these intermediate passageway widths.

McLean, Chittum, Funkhouser, Fairlie, and Folk (1992). The next study to address these issues was that of McLean et al. (1992), which investigated four different exit/seat assembly/passageway configurations. The four exit configurations were presented in a counterbalanced repeated-measures design. The singlepassageway configurations included: a) triple- seat assemblies with a single 20 " passageway and a 5 " aft seat encroachment; b) triple-seat assemblies with the seats forward of the exit broken over $15^{\circ}$ and having a single 10 " passageway with midline aft seat encroachment; and c) dual-seat assemblies with a single 10" passageway with midline aft seat encroachment. A dual Type-III exit configuration (d) was also examined: triple-seat assemblies formed three 6" passageways in which the outboard seat of both seat assemblies centered on the Type-III exits and bounding the center passageway was removed. Four groups of 39 subjects, ranging in age from 19 to 61 years, were employed. The intent of the study was to compare the relative flowrates of the various configurations, as well as the time required to remove the hatch (exit plug), with the results of the Rasmussen and Chittum (1989) study.

Table 6 shows the total group evacuation times and mean individual subject egress times for trials 1 through 4 at each configuration. Total group times include both the time to remove the exit plug and the time for all 39 subjects to exit completely.

Mean individual subject egress times were derived by subtracting the time at which the last body part of a preceding subject emerged from the exit from the time at which the last body part of the next subject emerged from the exit, specifically assuring a measure of flowrate, and not just hatch crossing time, as had been shown previously by McLean et al. (1989). The average flowrates also included only the times for the third through 37 th subject, as potential confounding effects of both exit plug removal and potential "stragglers" at the end of the egress stream were removed to reveal as pure a measure of flowrate as possible. 


\section{TABLE 6}

Total Group Evacuation Times And Mean Subject Flowrates

(McLean et al., 1992)

\begin{tabular}{|c|c|c|c|c|}
\hline \multirow{2}{*}{ Trial } & \multicolumn{4}{|c|}{ Passageway Configuration / Seat Assemblies } \\
\cline { 2 - 5 } & $\begin{array}{c}20 \text { " Single } \\
\text { Triples }\end{array}$ & $\begin{array}{c}\text { 10" Single } \\
\text { Triples w/Breakover }\end{array}$ & $\begin{array}{c}10 \text { " Single } \\
\text { Duals }\end{array}$ & $\begin{array}{c}\text { 6" Triple OBR } \\
\text { Triples }\end{array}$ \\
\hline 1 & $91.67 / 2.21$ & $74.03 / 1.78$ & $81.86 / 1.92$ & $72.36 / 3.00$ \\
\hline 2 & $74.90 / 1.80$ & $82.50 / 1.96$ & $87.37 / 2.13$ & $39.00 / 1.50$ \\
\hline 3 & $64.20 / 1.53$ & $89.83 / 2.14$ & $80.93 / 1.92$ & $46.60 / 1.96$ \\
\hline 4 & $77.16 / 1.86$ & $82.54 / 2.04$ & $62.36 / 1.48$ & $43.90 / 1.99$ \\
\hline Mean Time & $76.98 / 1.85$ & $82.23 / 1.98$ & $78.13 / 1.86$ & $50.47 / 2.11$ \\
\hline
\end{tabular}

Times in seconds $=$ Total group time $/$ flowrate in seconds per subject $n=39$ per group

The ANOVA found a significant effect of passageway configuration $(\mathrm{p}<.007)$, as the double exit/triple passageway configuration produced $36 \%$ shorter total evacuation times, compared with the single passageway configurations. This effect occurred in spite of an $11 \%$ reduction in average flowrate through the dual exit/triple passageway configuration, as well as a $32 \%$ increase in the average time required to remove the exit plug (see Table 7). There were no significant differences in flowrate among single-passageway configurations, nor were there significant differences in exit plug removal times among the single passageways.

In spite of the absolute differences in flowrates between the two studies and the lack of statistical significance among single passageway flowrate differences, McLean et al. (1992) concluded that the findings had supported and extended those of Rasmussen and Chittum (1989), specifically by providing corroboration that the 20 " single passageway configuration appeared to allow the most efficient egress of the single passageways studied. Reduced ergonomic restrictions of the 20" passageway, as compared with the narrower passageway configurations, was the main rationale for that conclusion, although the 10 " single passageway between dual seat assemblies had provided an essentially identical flowrate to that of the 20 " single passageway between triple seats. This seat-assembly effect was seen to rely on the reduced distance that subjects had to travel from the center aisle to the exit opening, leading the authors to suggest that providing both dual seat assemblies and a 20 " passageway configuration could produce even lower egress times. McLean et al. (1992) continued, in contrast, adding that the 6 " dual exit/triple passageway configuration increased the ergonomic restrictions and provided additional behavioral latitude relative to egress, decreasing flowrates, but also decreasing total evacuation times. These effects suggest an apparently complex interaction of the number of exits, number of passageways, passageway width, distance-to-be-traveled, and seat assembly type, that can again be reduced to the single construct of "personal ergonomic workspace" that passengers require (have imposed) in relation to

TABLE 7

Time To Remove The Exit Plug

(McLean et al., 1992)

\begin{tabular}{|c|c|c|c|c|}
\hline \multirow{2}{*}{ Trial } & \multicolumn{4}{|c|}{ Passageway Configuration / Seat Assemblies } \\
\cline { 2 - 5 } & $\begin{array}{c}\text { 20" Single } \\
\text { Triple Seats }\end{array}$ & $\begin{array}{c}\text { 10" Single } \\
\text { Triples w/Breakover }\end{array}$ & $\begin{array}{c}\text { 10" Single } \\
\text { Dual Seats }\end{array}$ & $\begin{array}{c}\text { 6" Triple OBR } \\
\text { Triple Seats }\end{array}$ \\
\hline 1 & 6.83 & 5.37 & 6.43 & 10.84 \\
\hline 2 & 4.47 & 8.86 & 4.14 & 5.77 \\
\hline 3 & 5.13 & 3.70 & 7.23 & 6.14 \\
\hline 4 & 4.14 & 4.87 & 4.03 & 5.84 \\
\hline Mean Times & 5.15 & 5.70 & 5.46 & 7.18 \\
\hline
\end{tabular}

Times in seconds

$n=39$ per group 
egress. In this vein, while many physical elements may participate in what appears to be a complex interaction, designing these elements to achieve the single construct of good personal ergonomic workspace appears sufficient to render potentially undesirable features of the interaction ineffective.

Thus, it appeared from another early Type-III exit study that passageway width, per se, has a relatively small effect on egress flowrate, with single passageways of intermediate width being similar in their ability to support evacuations. Narrower seat assemblies were also found to be better at supporting egress, although the gains obtained with dual-seat assemblies (relative to triple-seat assemblies) were offset somewhat in the case of OBR configurations, where removal of the outboard seat presented behavioral options that may have consumed additional decision time. An increase in the number of exits and passageways further promoted egress by distributing both the workspace and the evacuation across a greater number of egress routes, although flowrates through the single passageways were reduced. The positive effects of increasing the distribution may have been moderated by the presumed increase in decision-making requirements imposed.

Again, similar to Rasmussen and Chittum (1989), none of the single passageway configurations was shown to provide superior (statistically different) exit plug removal time, although the 6" OBR configurations produced arguably slower exit plug removal, depending on the specific configuration. This study also reinforced the Rasmussen and Chittum finding that exit plug removal is a relatively robust activity with regard to effects of passageway width, with the exception that subjects who are seated adjacent to the exit(s) in a 6" OBR configuration require a little more time and effort to remove the exit plug. This finding, coupled with the potential for added behavioral variability in the dual exit/triple passageway configuration, led McLean et al. (1992) to suggest that a reconfiguration of that entire exit scheme to employ single passageways, each leading to one of the Type-III exits, could produce a net gain in efficacy of egress. It should be noted that without such a reconfiguration, however, the ability of the dual exit/triple passageway configuration to support egress was still far superior to the single-exit/single-passageway configurations studied.

Muir, Bottomley, and Hall (1992). In 1992, Muir et al. revisited the approach of Muir et al. (1990), studying the effects of different apertures between bulkheads and different Type-III exit passageway widths on competitive evacuations conducted in cabin conditions of non-toxic theatrical smoke maintained at an optical density of 0.5 per foot. The studied passageways leading to the Type-III exit included configurations of 6" dual OBR and 13", 18", and 34 " single passageways, which were again achieved by holding the seat assembly forward of the exit as far aft as possible and moving the seat assembly aft of the exit to achieve the desired passageway width. Thirty-two evacuations, (8 at each of the 4 configurations) were conducted, employing 669 subjects $(79.2 \%$ male $)$ in groups of approximately 40 . Subjects ranged in age from 20 to 50 years. The competition payoff strategy allowed the first $75 \%$ (30) of the subjects to receive a 5 -pound bonus (half the participation fee) immediately upon exiting the airplane.

ANOVA conducted on the evacuation times (screened to remove outliers) for each configuration revealed a significant effect of passageway configuration $(p<.01)$ caused by an increase in evacuation time at the 6" OBR configuration, relative to the single passageway configurations (see Table 8). One outlying trial at the 18 " passageway width was removed from the analysis because it "was delayed from the outset... [and] also

\section{TABLE 8}

Evacuation Times From Competitive Evacuations In Non-toxic Smoke

(Muir et al., 1992)

\begin{tabular}{|c|c|c|}
\hline Configuration & All Evacuations & $\begin{array}{c}\text { Evacuations Without } \\
\text { Outliers }\end{array}$ \\
\hline 6" OBR & $70.7 / 16.2$ & $70.7 / 16.2$ \\
\hline $13 "$ & $55.3 / 9.2$ & $55.3 / 9.2$ \\
\hline $18 "$ & $64.1 / 20.5$ & $57.2 / 6.7$ \\
\hline $34 "$ & $58.2 / 19.7$ & $51.5 / 6.2$ \\
\hline
\end{tabular}

Times in seconds $=$ mean $/$ std dev.

$\mathrm{n}=30$ per cell 
hampered by several blockages in the exit aperture, although none were considered serious enough to warrant cancellation of the evacuation." Another case at the 34" passageway width was removed because the "evacuation began to display an abnormal pattern somewhere between the fifth and tenth volunteers to evacuate... undoubtedly primarily caused by an exit blockage in which two males attempted to exit simultaneously and, as one of them was extremely heavily built, became stuck in the aperture. This will have been compounded by an additional couple of minor blockages, none of which were considered serious enough to necessitate abandonment." One evacuation at the 13" passageway width was also aborted, as "four people were jammed in the exit aperture, unable to move. These volunteers were continually pushed by the mass of people still in the aircraft cabin and, immediately prior to the [alarm] signal, this group fell facedown onto the ramp." Combined, these outliers and the aborted trial indicate an extreme level of subject motivation, making evaluation of passageway effects more difficult, since data were lost at all three of the single passageway configurations. Again, human factors effects were responsible.

A significant effect of gender on time to egress was shown $(\mathrm{p}<.05)$, as males were faster than females, but there were no systematic differences in egress time resulting from age, weight, and height. Subjects who climbed over seats were faster than subjects who used the aisles, although questionnaires given to subjects after the evacuations failed to reveal an effect of escape strategy $(\mathrm{p}<.95)$. Except for the gender effect, these results are in direct contrast to the previous findings by Muir et al. (1989). Subjects more often reported that touch was their single most useful sense, followed next by vision, although $95 \%$ of the subjects reported not relying on the escape path marking system.

In addition, Muir et al. (1992) compared the competitive evacuation times with the non-competitive evacuation times obtained by Muir et al. (1990), which were obtained with a methodology identical to the Muir et al. (1989) non-competitive methodology, except for the greater number of subjects per group in the 1992 study. The mean egress times and standard deviations may be found in Table 9. A 2-way (passageway configuration $\mathrm{x}$ motivation level) ANOVA found a significant main effect of passageway configuration $(\mathrm{p}<.01)$, without a main effect of motivation level. Nor was there an interaction of passageway configuration with motivation level.

In the discussion of the results, the authors noted that the mean total evacuation time was slowest with the (narrowest) 6" OBR configuration, and noted that Muir et al. (1989) found faster evacuations with this configuration in clear air. They suggested that this effect could have been produced by a combination of the two competing streams of subjects and the lack of visual cues produced by the smoke, which eliminated subjects' ability to conform to the "neat streammerging behavior pattern as previously found." This interpretation agrees with that of McLean et al. (1989), who concluded that subjects' inability to profit from prior egress experience in clear air, while wearing smokehoods during evacuations in smoke, resulted from an inability to use previously-helpful visual information.

Muir et al. (1992) also addressed the apparent inconsistency seen with respect to the somewhat faster

\section{TABLE 9}

\section{Comparison of Evacuation Times From Competitive And Non-Competitive Evacuations In Non-toxic Smoke}

(Muir et al., 1992)

\begin{tabular}{|c|c|c|}
\hline Configuration & $\begin{array}{c}\text { Non-Competitive } \\
\text { Evacuations }\end{array}$ & $\begin{array}{c}\text { Competitive } \\
\text { Evacuations }\end{array}$ \\
\hline 6" OBR & $59.6 / 9.9$ & $70.7 / 16.2$ \\
\hline $13 "$ & $51.6 / 14.9$ & $55.3 / 9.2$ \\
\hline $18 "$ & $49.6 / 7.0$ & $57.2 / 6.7$ \\
\hline $34 "$ & $57.9 / 3.2$ & $51.5 / 6.2$ \\
\hline
\end{tabular}

Times in seconds $=$ mean $/$ std dev. $\quad n=30$ per cell 
evacuation at the 13" passageway configuration, as compared with the 18 " passageway, citing a possible perception by subjects that the 18 " passageway might be wide enough to allow more than a single person to egress simultaneously (thereby producing more competition for available egress workspace). They further suggested that the 13" passageway may have been perceived by subjects as only large enough to allow one person to egress at a time, and that other subjects may have "held back" to allow single subjects to egress individually, creating a faster evacuation. Either or both of these suggestions could be true, and the fact that the study by Muir et al. (1989) also obtained a blockage at the 18 " passageway might support the first interpretation, although the blockage at the 13 " passageway in the present study suggests that subjects were controlled more by the motivation factor than by apperception. The authors tacitly acknowledged this probability in their discussion of outlying cases, where they noted that " the escape times for 30 [subjects] in the outlying trials were excessive for all configurations in [a] class of evacuations... and suggests that it is not the specific configuration that led to extreme escape times... Instead, it is hypothesized that other factors were in evidence... [it] is more likely due to the nature of the people who arrive at the exit at the same moment, and it is suggested that changes in seat configuration can only minimize the probability of such circumstances appearing. If they do appear, it is likely that the evacuation will be delayed regardless of the particular seat configuration... Ideally, evacuations in which this behavior occurred would be subject to separate analysis." This discussion again attests to the powerful forces that human factors effects can exert on evacuations and the degree to which answers to the experimental question can be obscured by such uncontrolled factors.

Importantly, the caveat to the authors' discussion, regarding subjects' prospective perceptions of available egress workspace and the "probability" that this "effect may disappear if a larger number of evacuations using these configurations were performed" (see paragraph 4.3), is the lack of a significant difference found between the evacuation times at the 13 " and 18 " passageway configurations. Their explanation for the apparent "effect" is based on a perceived inconsistency with the results of Muir et al. (1989), for which a similar over-attribution of significance to the 18 " passageway configuration (relative to the 13" and 25" configurations) had led to a suggestion of its optimality. Had the authors not tried to "coax" significance from either of these two sets of findings, no apparent inconsistency (or need to explain) would have existed, since there were no significant differences to attribute in either case.

However, other actual inconsistencies were displayed, such as the lack of an evacuation strategy effect and faster egress produced by crawling over seats instead of using the aisle, both of which were in contradiction to the findings of Muir et al. (1989). Again, the 1989 effects were produced in cabin conditions of clear air, which would have allowed the use of visual information to aid egress. Given the relative consistency in the pattern of passageway configuration effects in the two studies, egress strategy and crawling over seats appear to have interacted minimally with the differences in egress workspace, instead supporting an interaction with information factors as responsible.

Fennell and Muir (1993). In 1993, Fennell and Muir reported another study of egress and passageway configuration, although the research question of interest focused on hatch (exit plug) removal and disposal. Two passageway configurations were employed, a 6" single passageway with maximum aft seat-assembly encroachment and a 13" single passageway with a 10 " encroachment, both between triple seat assemblies. Three different exit plug weights were also employed: $12.5 \mathrm{~kg}, 15 \mathrm{~kg}$, and $25 \mathrm{~kg}$. Subjects ranged from 19 to 54 years of age, and were restricted in height and weight to no more than the 50th percentile value for the US population. In half the trials a 50th percentile male anthropomorphic dummy was placed in the outboard seat adjacent to the Type-III exit, simulating an incapacitated passenger. The study was divided into two phases. The first employed the 6" and 13" passageway configurations and 96 subjects (1/2 male and $1 / 2$ female) distributed evenly among the three exit plug and two dummy conditions. Each subject performed one trial, using only one of the exit plug weights, either with or without the dummy. Phase 2 of the study was a replication of Phase 1, except that subjects performed three trials, all either with or without the dummy, and all using the same exit plug weight for all trials for a single subject. Trials were complete when the subject(s) first stepped onto the "wing" outside the fuselage. Subjects also completed questionnaires regarding their personal air-travel histories and their perceptions about different aspects of the study.

The effects of passageway configuration were assessed by t-test, using data from the Phase 1 and Phase 2 (test 1) trials, which showed that exit plug removal 
and disposal were significantly faster with the 13 " single passageway configuration than with the 6 " single passageway configuration $(\mathrm{p}<.001)$. No effects were reported for the simple presence or absence of the dummy, although the mean times for all conditions suggest a large effect (equally large variances notwithstanding), especially for female subjects. In fact, $18 \%$ of the subjects using the 6 " configuration and $2 \%$ of the subjects using the 13 " configuration (all female) were unable to complete the task. As a result, those subjects were assigned a time, as if they had completed the task, equal to the longest exhibited task time, to allow analysis of the data. Also, two of the males operating the $15 \mathrm{~kg}$ exit without the dummy present jammed the exit plug between the outboard seat and the exit frame, and a third opened the exit without unlatching his seat belt. These exit plug removal miscues caused the $15 \mathrm{~kg}$ exit plug times for males to be longer than the removal times for the $25 \mathrm{~kg}$ exit plug.

The authors reported that the mean time for all subjects to complete the task in the 6" passageway configuration was 38.0 seconds ( $38.6 \mathrm{sec}$. std. dev.); the 13 " passageway configuration produced mean times of 17.2 seconds (11.4 sec. std. dev.). Whether this included the adjustment for those who failed to finish the task is unclear. The mean times for the trials from Phase 1 may be found in Table 10 .

ANOVA was used to evaluate treatment effects in the data from both phases of the study for trials in which the dummy was absent. Main effects of passageway configuration $(\mathrm{p}<.001)$, exit plug weight $(\mathrm{p}<.001)$, and gender $(\mathrm{p}<.001)$ were found, as the 13" configuration and lower exit plug weights allowed faster exit plug removal/disposal and evacuation, with females being significantly slower than males. These effects were sufficiently robust to establish a 3-way (passageway configuration $\mathrm{x}$ exit plug weight $\mathrm{x}$ gender) interaction effect $(\mathrm{p}<.01)$, based on the fact that, when compared with the $12.5 \mathrm{~kg}$ and $15 \mathrm{~kg}$ exit plug weights, the $25 \mathrm{~kg}$ exit plug was operated more slowly by females (only) in the 6", but not the 13", passageway configuration.

A separate ANOVA was employed to evaluate treatment effects in the data from both phases of the study for trials in which the dummy was employed. This analysis revealed a significant main effect of passageway configuration $(\mathrm{p}<.001)$, resulting from the faster times in the 13" configuration. The authors reported that this effect held true for all three exit plug weights. The effect was greater for females, who were also shown to be generally slower at the task $(\mathrm{p}<.001)$. Combined, these effects were again strong enough to establish a 2-way (passageway configuration $\mathrm{x}$ gender) interaction effect $(\mathrm{p}<.001)$, indicating that, in the presence of the dummy, males were able to remove/dispose of the exit plug and egress relatively faster than females at the 6" configuration. However, only females had relatively improved egress times at the 13 " passageway configuration. A significant difference was also observed in the time taken to remove/dispose of the $12.5 \mathrm{~kg}$ exit plug, when compared with the $25 \mathrm{~kg}$ exit plug, in the 13 " passageway configuration $(\mathrm{p}<.05)$.

\section{TABLE 10}

Mean Times To Operate The Exit And Step Onto The Wing

(Fennell \& Muir, 1993)

\begin{tabular}{|c|c|c|c|c|c|c|c|}
\hline & \multicolumn{2}{|c|}{ 12.5kg Exit Plug } & \multicolumn{2}{|c|}{ 15kg Exit plug } & \multicolumn{2}{|c|}{ 25kg Exit Plug } \\
\hline & & $6 "$ & $13 "$ & $6 "$ & $13 "$ & $6 "$ & $13 "$ \\
\hline \multirow{2}{*}{ Male } & $\mathrm{N}$ & $11.35 / 4.03$ & 7.66 / 2.43 & 13.87 / 8.61 & $12.88 / 7.72$ & $15.91 / 7.14$ & 9.96 / 2.10 \\
\hline & $D$ & $20.49 / 12.28$ & $12.86 / 4.52$ & $15.05 / 7.89$ & 13.12 / 4.33 & $25.60 / 13.64$ & $21.95 / 11.48$ \\
\hline \multirow[t]{2}{*}{ Female } & $\mathrm{N}$ & $17.08 / 4.73$ & $11.53 / 3.22$ & $26.56 / 16.18$ & 13.33 / 6.26 & $80.65 / 48.19$ & $19.63 / 7.12$ \\
\hline & $D$ & $65.29 / 46.30$ & $21.97 / 13.33$ & 87.57 / 42.59 & $29.61 / 16.85$ & $76.25 / 43.52$ & $31.87 / 14.11$ \\
\hline
\end{tabular}

Note that times do not include reaction time to begin the evacuation or time for moving the dummy.

Times in seconds $=$ mean $/$ std. dev. $\quad \mathrm{N}=$ No dummy $\quad \mathrm{D}=$ Dummy $\mathrm{n}=8$ per cell 
The data from Phase 2 of the study (see Table 11), using only the 13 " passageway configuration, were then analyzed for the effects of subject experience. A repeated-measures ANOVA on data from trials without the dummy present revealed that there was no generalized effect of practice on exit operation and evacuation times, nor was the improvement in evacuation times produced by the reduction in exit plug weight (as shown in Phase 1) enhanced by practice on the task. However, females were not able to benefit to the degree that was shown for males by the third trial $(\mathrm{p}<.025)$. In contrast to these findings, subject experience in the presence of the dummy was shown to improve exit operation and evacuation times significantly $(\mathrm{p}<.01)$, without regard to gender. No differences related to practice were found regarding exit plug weight.

Subjects reported a variety of difficulties associated with the task, including impediments caused by the dummy, awkwardness in removing and disposing of the exit plug, lack of workspace, and personal injury while attempting to operate the exit. A repeated-measures ANOVA found that, by the end of the third trial, subjects perceived the size $(\mathrm{p}<.01)$ and weight $(\mathrm{p}<.025)$ of the exit plug to be greater. Fennell and Muir (1993) attributed these changed perceptions to possible fatigue. Subjects also reported that, when given the opportunity to examine the exit plug beforehand, they were often able to deduce how to approach the task better, how much the exit plug weighed, and that the exit plug should be disposed of outside the cabin (which was clearly indicated on seatback placards along the passageway). Interestingly, $63.5 \%$ of subjects employed with the 6" passageway configuration (without practice) placed the exit plug outside the cabin, whereas subjects employed with the 13" configuration placed the exit plug outside the cabin $38 \%, 70 \%$, and $80 \%$ of the time in Phase 2 tests 1, 2, and 3, respectively. However, 22\%, $30 \%$, and $33 \%$ of the subjects also held onto the exit plug until after egress in tests 1,2 , and 3, respectively. Similarly, $85 \%, 79 \%$, and $79 \%$ of the Test 1,2 , and 3 subjects placed the exit plug in a location that would have partly blocked egress, although instructions about exactly what to do with the exit plug after its removal had not been provided.

Except for the facilitative effect of regular exercise for some females $(p<.025)$ on the Phase I exit operation times at the 6 " passageway configuration, there were no systematic effects of individual subject differences on the results. This is more than likely due to the restricted $(<50$ th percentile) anthropometric population range from which the subject sample was drawn. Clearly, however, small females had much more difficulty with the task, often being unable to handle the exit plug effectively. Handedness was shown to have an effect, in that the dominant hand was used more often to

TABLE 11

Repeated Mean Times To Operate The Exit And Step Onto The Wing At The 13" Configuration (Fennell \& Muir, 1993)

\begin{tabular}{|c|c|c|c|c|c|c|c|}
\hline \multirow{2}{*}{$\begin{array}{c}\text { Repeated } \\
\text { Evacuations }\end{array}$} & \multicolumn{2}{|c|}{$12.5 \mathrm{~kg}$ Exit Plug } & \multicolumn{2}{c|}{ 15kg Exit Plug } & \multicolumn{2}{c|}{$25 \mathrm{~kg}$ Exit Plug } \\
\cline { 2 - 8 } & Male & Female & Male & Female & Male & Female \\
\hline \multirow{2}{*}{ Test 1} & $\mathrm{~N}$ & $7.66 / 2.43$ & $11.53 / 3.22$ & $12.88 / 7.72$ & $13.33 / 6.26$ & $9.96 / 2.10$ & $19.63 / 7.12$ \\
\cline { 2 - 8 } & $\mathrm{D}$ & $12.86 / 4.52$ & $21.97 / 13.33$ & $13.12 / 4.33$ & $29.61 / 16.85$ & $21.95 / 11.48$ & $31.87 / 14.11$ \\
\hline \multirow{2}{*}{ Test 2 } & $\mathrm{N}$ & $6.17 / 3.14$ & $8.88 / 5.12$ & $7.52 / 3.08$ & $14.11 / 13.41$ & $7.36 / 4.19$ & $18.32 / 9.87$ \\
\cline { 2 - 8 } & $\mathrm{D}$ & $9.11 / 5.44$ & $20.61 / 13.63$ & $14.49 / 15.15$ & $23.85 / 11.43$ & $19.76 / 16.63$ & $25.69 / 17.20$ \\
\hline \multirow{2}{*}{ Test 3 } & $\mathrm{N}$ & $6.23 / 1.95$ & $14.85 / 19.29$ & $5.96 / 2.19$ & $11.81 / 9.03$ & $7.30 / 1.49$ & $19.02 / 17.89$ \\
\cline { 2 - 8 } & $\mathrm{D}$ & $7.98 / 5.03$ & $14.35 / 11.56$ & $13.10 / 14.46$ & $18.35 / 12.54$ & $13.96 / 7.74$ & $21.99 / 17.51$ \\
\hline
\end{tabular}

Note that times do not include reaction time to begin the evacuation or time for moving the dummy.

Times in seconds $=$ mean $/$ std. dev. $\quad \mathrm{N}=$ No dummy $\quad \mathrm{D}=$ Dummy $\quad \mathrm{n}=8$ per cell 
grasp the exit handle for operation $(\mathrm{p}<.001)$, although this circumstance did not predict the time required to operate the exit.

In their discussion of the results, Fennell and Muir (1993) concluded that exit plug weight, passageway configuration, and gender all had effects on exit operation and evacuation time, although the decrease in task time produced by the larger 13" passageway configuration was not achievable without also reducing the exit plug weight (pg. 20). This interpretation is somewhat puzzling, given the significant main effect of passageway configuration, which is not dependent in any way on the main effects for exit plug weight and subject gender, or the significant 3-way interaction effect, found for Phase 1 with the dummy absent. Each factor had its own specific effects, which were altered by particular combinations with the other factors.

The effect of the dummy (incapacitated passenger) on exit operation and evacuation time was also seen to be important, as the indecision by subjects about whether or not to move the dummy before or during operation of the exit produced greater variability in the results. Recall that the presence of the dummy also made exit plug removal and disposal more difficult ergonomically, especially for females. Together, these two effects accounted for much of the treatment variability found in the results of this study, and again point to the importance of subject characteristics and behavior in understanding the intricacies of aircraft evacuations. Neither passageway configuration, exit plug weight, nor subject gender were shown to interact with egress experience, probably because a simple behavior such as lifting (the plug) has more to do with innate strength than strategy (especially for females), and the increase in egress workspace provided by the increased passageway width was probably offset, at a minimum, by the added physical impediment produced by the presence of the dummy. This interpretation is supported by the subjects' perceptions of the benefits of egress experience, as they reported practice-based improvements in knowledge about an appropriate technique to use for operating the exit, knowledge that apparently failed to help them behaviorally. It is unclear whether the cumulative fatigue attributed to subjects mitigated against facilitative effects of practice on exit operation.

In addition to the (physical) effects of passageway configuration and exit plug weight, negative (information) effects were produced by the quality of the safety cards and briefing materials, which failed to effectively explain the proper exit plug removal technique and disposal location. The authors suggested that this problem was responsible for the large number of subjects placing the exit plug on the passageway floor, an interpretation supported by the increased incidence of placing the exit plug outside the cabin (instead) as Phase 2 progressed. They also cited an apparent miscommunication about the degree of difficulty subjects should expect in lifting the exit plug, which may have accounted for the large number of subjects who dropped or otherwise mishandled it, resulting in delayed egress. Some subjects indicated that the exit plug depicted on the safety card appeared to be hinged, perhaps explaining why $35 \%$ of the subjects in Phase I were hit on the head by the plug as they released it from the exit frame. Together, these results indicate the strong role that information factors played in the outcome of the egress trials, workspace considerations aside.

The results obtained by Fennell and Muir (1993) are noteworthy with regard to the number and importance of factors affecting egress, both in terms of the specific effects that each factor produced and the interactions that resulted from their combination(s). The physical evacuation system elements again combined to delimit the amount of egress workspace, and the human factors effects were once again shown to be larger than could be overcome by establishing what appeared to be an adequate amount of workspace. These effects were exacerbated by provision of the incapacitated passenger, which produced an ergonomic impediment, especially for females. The human factors aspects of egress were shown to interact significantly with the quality of information provided to assist egress. The lack of specific instructions that could have eliminated improper exit plug removal and disposal, for example, revealed an inattention to experimental detail that allowed the loss of a large degree of external control of subject behavior. Combined, these factors and their interactions further depict a situation, in which each particular egress factor has a particular function in establishing an effective aircraft evacuation, and indicate that there should not be a reliance on one class of evacuation system features to overcome deficiencies in another.

\section{McLean, George, Chittum, and Funkhouser} (1995, Part I). Building on lessons learned from the studies described above, McLean et al. (1995, Part I) studied the specific effects of differences in single-passageway configuration on evacuations through the Type-III exit. Five different passageway widths, $6 ", 10 ", 13 ", 15 "$, and $20 "$, and three different aft 
seat-assembly encroachment distances, a 5" minimum, a 10" midline, and a 15" maximum, were investigated. Two groups of 37 subjects were employed in a counterbalanced research design; the first subject group ranged from 18 to 40 years of age and subjects comprising Group 2 were from 40 to 62 years old. Each group of subjects was required to perform 30 experimental trials (ten on each of three successive mornings) after a short learning exercise which consisted of two egress trials in which the aft seat assembly had been completely removed to allow subjects to "step through" the exit opening unimpeded. This exercise was allowed in order to reduce the overwhelming human factors effects related to egress through the Type-III exit shown in all of the previous studies and to provide superior identification of the effects of passageway configuration, per se.

Further, a "competitive cooperation" was created among subjects to serve as a motivational mechanism designed to encourage optimum individual performance. This technique was intended to reduce the variability associated with individual subject performance and improve discrimination of passageway configuration effects, and was based on offering a (unspecified) monetary bonus to the fastest 3 performers in each group. Seating arrangement was counterbalanced to provide all subjects an equal opportunity to obtain the bonus. One airline flight attendant was stationed at the rear of the cabin to urge subjects forward during trials, and another was initially seated in the outboard seat of the row immediately forward of the exit row. At the start of the trial, the forward flight attendant stood up and turned around (as if coming to the Type-III exit from a primary duty location), and instructed subjects (in the manner dictated by her emergency evacuation training) to egress quickly. Again, this technique was intended to minimize performance variability related to subjects' potential inattention to the task.

Finally, as the research question was directed toward the effects of passageway configuration on exit flowrates (and because neither Rasmussen and Chittum (1989) nor McLean et al. (1992) had found evidence of passageway effects on exit plug removal), a research confederate removed the Type-III exit cover from outside the aircraft simulator to preclude the possibility of that activity confounding the flowrate results. Given these experimental controls, and the minimally-variant data that resulted, the authors concluded that the results should be viewed as a "benchmark" of passageway configuration effects.
Total evacuation times included the first through the 35 th subjects, as the times for the last two subjects in each trial were deleted to control for potential changes in performance related to their rearward (straggler) positions in the evacuation stream. The results obtained from each group were remarkably consistent across trials; repeated measurement at the end of each experimental day, using the 20" passageway with a 5" aft seat assembly encroachment as a control, confirmed the consistency with which subjects were performing. A 3-way ANOVA revealed significant main effects of subject group $(\mathrm{p}<.001)$, passageway width $(\mathrm{p}<.001)$, and seat encroachment distance $(\mathrm{p}<.001)$, with no significant interactions between any of the factors. The effects were indicative of slowed egress produced by advanced age, narrower passageways, and the greatest aft seat encroachment distance, and resulted from the reduced agility and athleticism of the older subjects, as well as the reduction in egress workspace produced by the more restrictive passageway configurations.

Simple effects ANOVA on group evacuation times found a significant effect of passageway width for both the younger $(\mathrm{p}<.001)$ and older $(\mathrm{p}<.025)$ groups. Post hoc analyses indicated that the 6" and 10" passageway widths produced longer evacuation times for the younger group, but only the 6" passageway width slowed the older group significantly $(\mathrm{p}<.05)$. This lack of effect at the 10" passageway width for the older subject group resulted from an inadvertent change in instruction set produced when the forward flight attendant unexpectedly began instructing subjects to crawl over the seats to egress, eliminating the effects of passageway configuration and reducing the time required for the group to evacuate. This change in older group egress instructions affected the reported results for only the 10" passageway configuration. A simple effect of encroachment distance was also significant for the younger group alone $(\mathrm{p}<.03)$, resulting from slowed egress at the maximum encroachment distance, relative to the other two seat encroachment distances. The older group results were essentially identical to those of the younger group, except for an approximate 15 -second increase in egress times at all three seat encroachment distances. However, the older group times were not statistically different, probably because of increased variability at the maximum encroachment distance.

The essentially interchangeable character of the results from both subject groups suggested that combining the raw data from both groups into a single data set could 
provide a more generalizable answer to the research question (cf. Loftus, 1993), without violating the assumptions of the statistical model (see Table 12). This approach was then supported by a 2-way repeatedmeasures ANOVA, which revealed a lack of interactions between subject group (age) and either passageway width $(\mathrm{p}<.14)$ or seat encroachment distance $(\mathrm{p}<.96)$, and which further suggested that any effects of age on mean egress performance, as embodied in the data from the two broadly-based age groups being studied, were confined to the main effects.

This lack of interactivity was reconfirmed by a 2-way ANOVA on the combined group data, which showed a main effect of passageway width $(\mathrm{p}<.05)$, without an effect of seat encroachment distance. Post hoc analyses indicated that only the 6 " passageway width produced significantly slowed evacuation times; the slowing produced by the 10" passageway for the younger subject group was rendered non-significant by combining both groups' data, which resulted in a reduced mean egress time and an increase in the variability associated with the 10" passageway. A similar fate befell the times related to seat encroachment distance, which also were not significantly different. Thus, the combined group results had come to resemble the results from other studies of passageway configuration effects, where 6" single passageway widths were clearly outside the range that could support effective egress through the Type-III exit, although the exact answer as to whether a 10" passageway is acceptable remained in doubt.

In their discussion of the results, McLean et al. (1995, Part I) were careful not to suggest that the 10" passageway width might provide appropriate egress workspace, given the results from the younger subject group alone, which had shown that egress through 10" passageways was significantly slower than through the wider configurations employed. Citing this latter effect, and the change in instruction set for the older subject group, the authors concluded that only the 13 ", 15 ", and 20" passageway widths could truly be seen as equivalent, since the 10 " passageway width data for the older group were incomplete.

Although the experimental design had been constructed to eliminate many of the human factors issues previously associated with studies of egress through the Type-III exit, another interactive human factor was displayed. That factor was one related to the "operator" of the system, i.e., the flight attendant who was in charge of the evacuation process. The fact that the change in egress instructions occurred at only the 10 " passageway width produced an unexpected interaction, the outcome of which was to partially eliminate egress slowing produced by a single passageway 10 " in width, thereby obscuring the actual egress flowrate that would otherwise have occurred. Thus, a human factors aspect of the evacuation was shown once again to confound the ability to discriminate effects of changes to the physical evacuation system elements, substantiating a need to explore the data further for as much understanding as could be achieved.

McLean and George (1995, Part II). Toward that end, McLean and George reexamined the McLean et al. (1995, Part I) data, looking specifically at the human factors aspects. The unified dataset that resulted from the combination of the two Part I subject groups' data contained over 2,000 individual observations, allowing recombinations of the data to form more discrete categories within the general domains of age, weight, waist size, and height. These individual subject variables were then evaluated for their ability, individually and in combination, to affect egress flowrates.

A multivariate ANOVA was conducted on these new groups of individual subject data, using the individual subject egress times for each passageway configuration as the dependent variable. Main effects were found for subject age $(\mathrm{p}<.0001)$, weight $(\mathrm{p}<.0004)$, waist size

TABLE 12

Group Egress Times At Each Passageway Width

(McLean et al., 1995, Part I)

\begin{tabular}{|c|c|c|c|c|c|}
\hline \multirow{2}{*}{$\begin{array}{c}\text { Subject } \\
\text { Group }\end{array}$} & \multicolumn{5}{|c|}{ Passageway Width } \\
\cline { 2 - 6 } & $6 "$ & $10 "$ & $13 "$ & $15 "$ & $20 "$ \\
\hline Younger & $43.78 / 2.2$ & $42.77 / 2.4$ & $38.03 / 1.8$ & $35.85 / 2.8$ & $36.39 / 2.5$ \\
\hline Older & $61.65 / 5.6$ & $51.72 / 1.9$ & $49.68 / 1.6$ & $51.06 / 2.0$ & $49.82 / 4.0$ \\
\hline Combined & $52.72 / 3.9$ & $47.24 / 2.2$ & $43.86 / 1.7$ & $43.46 / 2.4$ & $43.11 / 3.3$ \\
\hline
\end{tabular}

Times in seconds $=$ mean $/$ std. dev. $n=37$ per age group 
$(\mathrm{p}<.00125)$ and gender $(\mathrm{p}<.001)$; older, heavier, and larger subjects were found to be significantly slower to egress, as were females. There was no effect of subject height $(\mathrm{p}<.3)$, nor were there any interactions found between any of the subject variables and passageway configuration. Importantly, the effects of age (pooled in 10-year subgroups across the entire subject sample age range) appeared to be essentially linear (see Table 13), further substantiating that the combining of Groups 1 and 2 data by McLean et al. (1995, Part I) was methodologically appropriate, i.e., there was no masking of an interaction that would render younger subject egress differentially more or less efficient by the circumstance of being in an aircraft evacuation with older cohorts. (This point will be revisited below, where part of the discussion regarding the effects of egress experience will provide a final clarification vis-à-vis the ability of the mere presence of older subjects in an evacuation to synergistically impede, or facilitate, younger subject egress.) A stepwise multiple regression analysis revealed that, of the individual subject attributes evaluated, age accounted for the largest amount (43\%) of experimental variance; residual effects were also shown (in decreasing order of influence) for weight/waist size (girth), gender, and height.

As described above, these subject characteristics produced effects on mean egress efficiency, without interactions with passageway configuration, although mitigation of potential interaction effects could have resulted from differential effects of the learning exercise provided subjects at the beginning of their participation.

Two hypotheses had been advanced with regard to that possibility. McLean et al. (1995, Part I) had suggested that first, the lack of an interaction of (advanced) age and (narrow) passageway configuration might result from the "skill practice" that egress experience provided, or second, that enhanced knowledge about egress contingencies would allow older subjects to develop better strategies that could overcome age-related decrements in agility. The answer to which, if either, of these hypotheses would be correct was found in the configuration-specific evacuation results, after egress time difference scores were derived from successive egress trials at a particular passageway configuration. These difference scores were subjected to a 2-way (age x passageway width) ANOVA that showed an age $\mathrm{x}$ passageway width $\mathrm{x}$ egress trial interaction effect $(\mathrm{p}<.002)$ on egress, resulting from slowed egress at narrow passageway widths on the first trial for older subjects. This was the first indication that there was a synergistic effect on egress efficiency produced by combining advanced age (50-62 years old) with narrow passageway widths. Simple effects analysis on data from Trial 1 for subjects in each decade of age found main effects of age $(p<.001)$ and passageway width $(\mathrm{p}<.001)$, and an age $\mathrm{x}$ passageway width interaction effect $(\mathrm{p}<.02)$; a main effect of age $(\mathrm{p}<.001)$ was the only significant effect found for Trial 2 scores.

The mean scores for each decade of subject age showed that, many trials after generalized skill at using the Type-III exit was well established, older subjects were still relatively slower on the first trial using the 6 " and 10" passageways (see Table 14). This reduction in egress efficiency was eliminated on the very next (second) egress trial (conducted in all instances with the same passageway configuration as on the first trial), indicating that older subjects had discovered some evacuation contingency on the first trial by which they were able to guide their egress performance on the second trial, eliminating the age-related increase in egress time. This ability of older subjects to "correct" their performances on the second trial allowed them to appear no more differentially compromised, on average, than their younger counterparts, whose superior agility provided equivalent egress efficacy on both the first and second trials for all passageway configurations. Thus, older subjects were displaying strategic learning effects related to specific egress experience, not just ongoing improvements in motor skill.

\section{TABLE 13}

Mean Individual Egress Times For Each Age Group McLean and George (1995, Part II)

\begin{tabular}{|c|c|c|c|c|c|}
\hline & \multicolumn{5}{|c|}{ Age Groups } \\
\cline { 2 - 6 } & $18-29$ & $30-39$ & $40-49$ & $50-59$ & $60-62$ \\
\hline Egress Times & $0.98 / 0.34$ & $1.15 / 0.39$ & $1.37 / 0.54$ & $1.58 / 0.72$ & $1.98 / 0.88$ \\
\hline
\end{tabular}

Times in seconds $=$ mean $/$ std. dev. $n=37$ per age group 


\section{TABLE 14}

\section{Individual Mean Times By Trial And Difference Scores \\ For Each Age Group At Each Passageway Width \\ McLean and George (1995, Part II)}

\begin{tabular}{|c|c|c|c|c|c|c|c|c|c|c|c|c|c|c|c|}
\hline \multirow{2}{*}{$\begin{array}{c}\text { Pooled } \\
\text { Ages }\end{array}$} & \multicolumn{3}{|c|}{ 6" Trials } & \multicolumn{3}{|c|}{$10 "$ Trials } & \multicolumn{3}{|c|}{ 13" Trials } & \multicolumn{3}{|c|}{$15 "$ Trials } & \multicolumn{3}{|c|}{$20 "$ Trials } \\
\hline & 1 & 2 & $\mathrm{D}$ & 1 & 2 & $D$ & 1 & 2 & $D$ & 1 & 2 & $\mathrm{D}$ & 1 & 2 & $\mathrm{D}$ \\
\hline $18-29$ & 0.99 & 0.96 & 0.03 & 1.03 & 0.95 & 0.08 & 0.88 & 0.87 & 0.01 & 0.94 & 0.97 & -0.03 & 1.15 & 1.09 & 0.06 \\
\hline $30-39$ & 1.39 & 1.07 & 0.32 & 1.30 & 1.27 & 0.03 & 1.04 & 1.04 & 0.00 & 0.97 & 0.95 & 0.02 & 1.11 & 1.11 & 0.00 \\
\hline $40-49$ & 1.33 & 1.42 & -0.09 & 1.37 & 1.37 & 0.00 & 1.46 & 1.32 & 0.14 & 1.46 & 1.48 & -0.02 & 1.56 & 1.46 & 0.10 \\
\hline $50-59$ & 2.66 & 1.33 & 1.33 & 2.62 & 1.60 & 1.02 & 1.22 & 1.08 & 0.14 & 1.36 & 1.54 & -0.18 & 1.35 & 1.35 & 0.00 \\
\hline $60-62$ & 2.59 & 1.71 & 0.88 & 2.48 & 1.86 & 0.62 & 1.82 & 1.72 & 0.10 & 2.03 & 2.07 & -0.04 & 1.91 & 2.13 & -0.22 \\
\hline Mean & 1.79 & 1.30 & 0.49 & 1.76 & 1.41 & 0.35 & 1.28 & 1.21 & 0.07 & 1.35 & 1.40 & -0.05 & 1.42 & 1.43 & -0.01 \\
\hline
\end{tabular}

Times in seconds

$\mathrm{D}=$ Difference between trial 1 and trial 2 egress times.

These difference score effects were replicated for seat encroachment distance, with the age $\mathrm{x}$ encroachment distance $\mathrm{x}$ egress trial interaction effect again being significant $(\mathrm{p}<.002)$, as were the simple effects of age $(\mathrm{p}<.001)$ and an interaction effect of age and encroachment distance $(\mathrm{p}<.002)$ on trial 1 scores, with only a main effect of age $(\mathrm{p}<.001)$ found for trial 2 scores. The mean scores for each decade of age showed that performance for the older subjects was again significantly slower at the midline and maximum seat encroachment distances, relative to the minimum encroachment distance, although the times for the midline seat encroachment distance were heavily confounded by the 10" passageway width (midline seat encroachment) condition. Combined, the results indicate that there are definite limits to the range of passageway widths and seat encroachment distances that can support fast, effective egress; these limits were shown more clearly to exclude the 10 " single passageway configuration between triple-seat assemblies, as well as seat encroachment distances beyond the Type-III exit midline, even for larger passageway widths.

Similar analyses were conducted on all of the other subject attributes in combination with passageway width and seat encroachment distance. No other systematic effects were found.

Returning to the question of mixing the data from the 2 subject groups, it is instructive that the age $\mathrm{x}$ passageway configuration interaction effects were limited to subjects 50 years of age and older, i.e., those in Group 2, which also contained 40- to 49- year old subjects, who performed like their 18- to 40-year old counterparts in Group 1. This lack of a synergistic effect among these Group 2 age subgroups is the final component in the rationalization of combining data from Groups 1 and 2, as any interaction effects produced by including subjects of mixed (older) age should have been seen on the 40 to 49 year old Group 2 subjects, but were not. Thus, the original decision to combine the data has been fully justified by three coalescing lines of evidence, and has allowed the discovery of both the age by passageway configuration interaction effect and the manner by which the older subjects were able to benefit from egress experience to overcome the effects of this interaction. As a result, the ability of experience to overcome the human factors influences on evacuation performance can be seen both as allowing illumination of the pure effects of passageway configuration and providing a treatment that holds promise for studying other egress factors that are affected by the instability in performance associated with multiple egress trials (experience).

Muir (1996). In 1996, Muir reported the results of another follow-on study to the Muir et al. (1989) work. Recall that in the earlier 1989 study, the authors had investigated the effects on egress of five different single-passageway widths: 3 ”, 13", 18”, 25”, and 34", as well as the 6" OBR dual passageway configuration, conducting trials in both competitive and noncompetitive subject motivation conditions. Subjects ranged in age from 20 to 50 years. In 1989, competitive subjects had completed four evacuations each, two through one of several aperture sizes between bulkheads and two through one of the passageway widths leading to a Type-III exit. In the Muir (1996) study, similar subjects performed four evacuations in the competitive 
motivation condition. However, one of the evacuations was performed through a single bulkhead aperture of 28 " and the other three evacuations were performed through 6" or 10" single passageway configurations (either one or two at each width, depending on the specific subject group). The results were compared with those of the 1989 study.

Cumulative egress times for the first 30 subjects were compared. ANOVA revealed a significant main effect of passageway configuration ( $\mathrm{p}<.0001)$, resulting from reduced flowrates at narrower passageway widths. Not including the trials with blockages at 6" and 10" passageways, comparison of individual means showed that the 3" and 6" single passageway configurations were responsible for the overall main effect; the 10" passageway produced egress times not significantly different from the 13", 18”, 25", and 34" singlepassageway widths, or the 6" OBR passageway. If anything, the 10" passageway configuration appeared to give slightly faster egress (see Table 15), notwithstanding the trial at 10 " that resulted in a blockage.

These results again appear to suggest that 10" passageways provide egress equivalent to that resulting from 13" through 25" passageways. However, differences in the research design between the Muir et al. (1989) and Muir (1996) studies, as well as the difference in subject age range between the Muir et al. $(1989,1996)$ studies and the study of McLean et al. (1995, Parts I \& II), indicate that this is likely not the case. The design differences relate to the variably-practiced nature of the subjects employed by Muir et al. (1989) and Muir (1996), as subjects completed two Type-III exit egress trials in the competitive phase of the 1989 study and three total (one or two at each width) Type-III exit egress trials in the 1996 study. As demonstrated above, naïve subjects do not perform as efficiently as do well-practiced subjects, and subjects do not gain nearly as much benefit from only one (practice) egress trial, e.g., Muir et al. (1989), as they do from two (practice) trials, e.g., McLean et al. (1995, Parts I \& II). This situation skews the results from trials after practice progressively to the left, i.e., mean results that include three or more trials will show faster egress, as a rule, than mean results from one or two trials. This subtle learning effect could otherwise be misconstrued (as in the 1996 study) as indicating that 10 " single passageways are just as effective in supporting evacuations as are larger passageway configurations. When taken together with the findings by McLean and George (1995, Part II), regarding evacuation performance of subjects over 50 years of age (considering the more restricted subject age range in the Muir et al. 1989, 1990, 1992, \& 1996 studies) this confounded finding provides little reason to conclude that the 10 " passageway configuration provides adequate egress.

McLean, Corbett, and George (1999). A 1999 presentation by McLean et al. described the effects on aircraft evacuations of passenger density in the aircraft cabin and passenger management strategy, vis-à-vis initial flight attendant duty station relative to moving to

TABLE 15

Cumulative Evacuation Times For the First 30 Competitive Subjects to Evacuate

(Muir, 1996)

\begin{tabular}{|c|c|c|}
\hline $\begin{array}{c}\text { Passageway } \\
\text { Configuration }\end{array}$ & $\begin{array}{c}\text { Trial } \\
\text { Means }\end{array}$ & $\begin{array}{c}\text { Standard } \\
\text { Deviations }\end{array}$ \\
\hline $3 "$ & $71.48^{*}$ & 15.04 \\
\hline $6 "$ & $70.10^{*}$ & 16.18 \\
\hline $10 "$ & 52.22 & 11.09 \\
\hline $13 "$ & 55.92 & 10.38 \\
\hline $18 "$ & 53.75 & 8.27 \\
\hline $25 "$ & 54.90 & 11.54 \\
\hline $34 "$ & 62.32 & 8.14 \\
\hline 6" OBR & 53.29 & 10.06 \\
\hline Times in seconds & * $=$ significant $(\mathrm{p}<.05)$ & \\
\hline
\end{tabular}


the Type-III exit and conducting evacuations. For this study, a single-passageway configuration was established by positioning the seat assembly forward of the exit row as far rearward as possible, with the aft seat assembly positioned to create a 13" passageway width. Passenger density was set at either 30 or 50 subjects per group, and the flight attendant was positioned at one of three initial duty locations, either outboard in the seat row forward of the exit row, seated outboard in the exit row, or in the aft of the cabin. Two of the three duty locations were essentially identical for both lowand high-density conditions; the third location was different for each density condition and allowed a within-subjects examination of particular passenger management strategies. An additional passenger management condition was established by the absence of an active flight attendant. Five egress trials were conducted for each of six groups in each density condition; trials one and five were pre/post flight attendant-absent trials, with the counterbalanced flight attendant (present) duty locations nested in Trials 2, 3, and 4 .

Cumulative group evacuation times were calculated on the fifth through thirtieth subject for the flight attendant duty locations common to both density conditions. The low-density trials averaged 5.08 seconds for five subjects to egress, accumulating to 37.04 seconds for thirty subjects. The high-density trials averaged 9.14 to 46.09 seconds for five to thirty subjects, respectively, confirming the expected hyper-additive increase in egress times associated with higher passenger density. A 2-way repeated-measures ANOVA was employed to evaluate the effects on individual egress times of passenger management and passenger density. Significant main effects were shown for both passenger management $(\mathrm{p}<.001)$ and passenger density $(\mathrm{p}<.002)$, and a management by density interaction effect $(p<.001)$. These effects resulted from the increase in evacuation efficiency produced by the presence of a flight attendant, especially in the high-density condition, which otherwise produced significantly slower evacuations (see Table 16).

Each passenger density condition was then examined individually for the effects on egress of specific flight attendant duty location, none of which was shown as superior in either the low- $(\mathrm{p}<.9)$ or high- $(\mathrm{p}<.15)$ density condition. Similarly, comparison of the two flight attendant duty locations common to both density conditions showed that passenger density and flight attendant duty location produced no significant interactions $(\mathrm{p}<.2)$.

These results bear directly on the question of whether the 13" passageway configuration provides adequate access-to-egress, and address the issue of flight attendant (operator) effects on evacuations through a Type-III exit. The mean times per subject to egress in the low passenger density condition, both with and without a flight attendant present, were in the average range of egress times found in previous non-competitive studies, i.e., within the range of mean individual egress times seen with intermediate passageway configurations. The high-density egress times attained with a flight attendant present were also in this range, although the high-density egress times without a flight attendant present resembled those from competitive evacuation trials, as well as trials conducted with smoke in the cabin. This combination of effects suggests that subject (in)attention to performing the task, particularly with regard to the organizing function provided by the flight attendant, was the responsible mechanism for the passenger management effects seen. It also suggests that the passenger density effects can be explained by variable inattention to the task, with less-involved passengers producing relative increases in egress time above that required to merely traverse the exit opening. This single construct is the most parsimonious explanation for the effects of both passenger management and passenger density, as well as the interaction between them. As such, the degree to which flight attendants facilitated evacuations in the other studies reviewed

\section{TABLE 16}

\section{Passenger Management (Flight Attendant) Effects on Mean Egress Times}

(McLean et al., 1999)

\begin{tabular}{|c|c|c|}
\hline Density & Present & Absent \\
\hline Low & 1.44 & 1.53 \\
\hline High & 1.52 & 1.80 \\
\hline
\end{tabular}

Times in seconds 
herein should be a partial predictor of the reliability of the results obtained in those studies, especially where other treatments, such as changes to passageway configuration, rely on comparisons of subject performance to discriminate among alternatives.

McLean and Corbett (2000). McLean and Corbett evaluated the data from the McLean et al. (1999) study for effects on egress of individual subject attributes. Main effects of age $(\mathrm{p}<.001)$, weight $(\mathrm{p}<.001)$, and gender $(\mathrm{p}<.001)$ were found for both the low- and high-density conditions, but there were no interactions between any of the subject variables and either passenger density or passenger management (the presence or absence of a flight attendant at the Type-III exit). These effects generally replicate those found by McLean and George (1995, Part II), regarding the impact of passengers' physical attributes on evacuations; i.e., older and heavier passengers generally egress more slowly, as do females. The lack of interactions attests again to the generally linear character of the evacuation system.

\section{DISCUSSION}

The central theme evidenced throughout the experimental Type-III exit evacuation literature to date is the overwhelming domination of evacuation performance by human factors and ergonomics effects. Differences in individual subject attributes and behavior, especially errant behavior unrelated to the research questions at hand, have often influenced the findings to obscure identification of the intricacies related to the issue being addressed. This circumstance is particularly acute in relation to the passageway configuration issue, where the large variability in the available data from almost all the studies previously conducted has resulted in a variety of suggested effects, many of which remain unsubstantiated. Beginning with Rasmussen and Chittum (1989), naïve subjects performed equivalently using both the 6" and 20" single-passageway widths between triple seat assemblies; specific effects of passageway configuration became more evident as subjects became more experienced. Similarly, the 10" single-passageway width between triple seat assemblies has been found almost universally to provide evacuation performance statistically comparable to larger single-passageway configurations, although the small differences in flowrates between the 10" passageway width and larger dimensions in those studies have spawned a array of negative assessments and attendant rationalizations designed to deny its acceptability. For example, Rasmussen and Chittum (1989) reported potentially negative effects on exit plug placement, and McLean et al. (1992) described reduced ergonomic workspace relative to larger passageway configurations. Importantly, actual differences in egress performance related to the 10 " single passageway configuration were found to be significant in the study by McLean et al. (1995, Parts I \& II). This ability to delimit the 10 " single passageway effects resulted from better experimental controls that reduced the variability in individual subject performance, allowing further clarification of passageway configuration effects, per se. Without gaining that degree of experimental control, the human factors effects would likely have continued to obscure the fact that a 10 " single passageway between triple seat assemblies is actually too narrow to provide egress capability equivalent to the intermediate passageway widths (13" through 25 ") studied to date.

In addition to highly-variable behavior by research subjects, the reason that such human factors effects have influenced the results so much is that no matter what the experimental question, the general rule has been to use minimal latin square (type) research designs, comprised of only a few egress trials per group and/or only a few groups per treatment level, resulting in data that are largely confounded by individual subject variability and the effects of practice. Problems related to these incomplete designs have often been compounded further by comparisons of the data thusly obtained with other data acquired using similar methodologies, which have, unfortunately, also generally suffered from the same types of deficiencies. An example is the comparison of data acquired using different egress practice regimes, which led to a misinterpretation with respect to the acceptability of the 10 " passageway configuration. Fortunately, however, the general trend in these studies has been to advance the position that only larger intermediate passageway widths provide essentially equivalent egress capability.

The design of McLean et al. (1995, Parts I \& II) was able to discriminate more clearly between passageway configurations, identifying the appropriate range of physical limits that, combined, would provide appropriate ergonomic workspace. This design employed well-practiced subjects to reduce individual performance variability, use of a minimal motivation technique intended to keep the subjects "involved" in the task at hand, and employment of a flight attendant to encourage subjects and further keep them on task. 
This study was the first to "benchmark" the effects of passageway configuration, per se, substantiating only the intermediate range of single-passageway configurations as equivalent for a broader, more general passenger population.

The problems with using minimal research designs have also been compounded by the tendency in some studies to introduce extraneous egress factors into the experimental process and then address the obtained results to the issue of passageway configuration. For example, much has been made of the inability of subjects to appropriately remove and dispose of the Type-III exit plug, as if the passageway configuration was responsible. The data acquired to date generally show that this is not the case, although in the one instance where a small, differential effect on exit plug operation was found, information and user factors were more responsible for the effects seen. The safety briefing card and seatback placards were available to aid subject performance, but they were apparently not used to gain the relevant information. Nor were verbal briefings given. Nonetheless, the results related to the exit plug removal and disposal in that study were addressed to the passageway configuration issue, leading to a general expectation that increasing the passageway width would alleviate the lack of applied information.

In fact, none of the studies has made sure that subjects who were responsible for performing exit plug removal and disposal were demonstrably aware of the proper procedure before the egress trials began. Where problems arose and the passageway configuration was implicated by the study authors, there was no indication provided as to how wider passageways would improve the situation. Similarly, the negative impact on exit plug removal and disposal produced by placing an incapacitated passenger (dummy) in the seat next to the exit has been seen as indicating a need for wider passageways, but more importantly, the size and strength of the subjects who operated the exit were largely responsible for the results, as very small females were unable to perform the task. While the inclusion of such factors in the research designs provided important information relative to egress and the possible interactions of such factors in evacuations, ameliorative actions other than maximizing passageway width could reasonably be expected to provide much better outcomes regarding the effects of these negative factors. It cannot be that maximizing passageway configuration is the solution for every potential evacuation-related problem.
The effects of passageway configuration have been shown to relate specifically to the construct of "personal ergonomic workspace" needed to egress effectively and efficiently. Passageway width and aft seat-assembly encroachment into the area of the exit opening are generally responsible for delimiting this workspace, although the use of multiple exits and passageways can distribute the workspace to facilitate egress. This holds true even though multiple passageways may be narrower and less efficient, individually, than would be the case for a larger single exit/passageway configuration. This occurs because the rate at which the exit is being fed evacuees is cumulatively higher, allowing more passengers to egress per unit of time. Other interactive factors, such as smoke in the cabin and high passenger motivation, have been shown to offset this facilitation, somewhat, but the positive effects of multiple passageways remain, as long as the exit continues to be available and the number of passengers ready to egress exceeds that which a single passageway would accommodate.

In sum, the factors that control evacuations through a Type-III overwing exit are many. Passageway configuration provides only one of the important contributions, its effects as a physical subsystem element being to delimit the egress workspace. As long as the egress workspace is adequate, passageway configuration may be said to be acceptable as well. Information subsystem elements such as safety briefing cards, placards, and personal passenger briefings are also important contributors, since "knowing what to do" has been shown to be more important than having an optimum space in which to do it. Without knowledge about the airplane evacuation system and its function, fast effective evacuations rarely seem to be the rule. This outcome is readily apparent in the positive effects produced by egress experience, the lack of which institutes variable, often errant, passenger behavior as the norm. The Type-III exit operator subsystem includes both the flight attendants, where available, and (especially) the passengers, who have been shown to open the exit and dispose of the exit plug in a variety of ways, both intended and not. This propensity for exit operation to exemplify idiosyncratic functional approaches further indicates the degree to which knowledge about the evacuation system is crucial. The evacuation user subsystem is also comprised of the passengers who, through virtue of their personal attributes, knowledge, and behavior, contribute the largest amount to the success or failure in an evacuation, especially through the Type-III exit. As has been recognized, performance effects related to the passengers can obscure identification of the contributions of the other evacuation 
system elements, in essence rendering insignificant the exact nature and specification of those elements. Such is the situation regarding passageway configuration.

Interactions among these subsystems and elements, where found, have been shown to be generally linear, once again being more related to the degree to which human factors effects are evidenced. Without the need to account for such effects, an evacuation system could be designed to function flawlessly. However, the fact that humans must use the system engenders the need to fine tune each and every evacuation subsystem and element to maximize total system proficiency and linearity. This is the reason that multiple FARs have been established, addressing the range of evacuation system elements, rather than legislating a single class of evacuation system elements/functions to address the spectrum of contingencies that passengers and crewmembers will encounter in evacuations. Where deficiencies are identified with regard to specific evacuation subsystems and elements, these need to be addressed. However, they need to be addressed in a way that will solve the specific deficiency identified, not just strive to compensate for it with supplementary performance by another subsystem or element. Thus, if physical subsystem elements provide inappropriate egress workspace, modify them; if information subsystem elements are not informative and useful, perfect them; and if the operator/user subsystem elements are not effective or efficient, instruct them. Only through this type of balanced approach will the success of airplane emergency evacuations be better guaranteed.

\section{CONCLUSIONS AND REGULATORY APPLICATIONS}

- Human factors effects predominate in controlling evacuation performance and obscure the effects of other evacuation factors. Controlling human factors (and other confounding) effects is necessary to clarify the effects of other factors, such as passageway configuration.

- Forward encroachment of the exit row aft seat assembly to the midline of the exit gives better egress flowrates, although lesser seat encroachment distances are acceptable.

- Passageways between 13 " and 25 " provide essentially equivalent egress flowrates, whereas those with greater or narrower (especially for older passengers) widths are less effective.

- Blockages of the Type-III exit by subjects during competitive evacuation trials is related more to the attitudes and motivation levels of individual subjects, not passageway configuration, as blockages or extremely delayed evacuations have occurred at almost all studied passageway widths.

- Exit plug removal and disposal is affected little by passageway configuration, although the placement of the plug after removal has been shown to be variable, resulting from poor instruction about what to do with it. Exit designs that include automatic disposal, and/or better instructions for passengers who must open exits, could alleviate this problem.

- Information materials, such as safety briefing cards, related to emergency evacuation activities have been poorly rendered, as passengers either cannot understand the intent of the materials or do not seem obliged to read and follow the instructions.

- Provision of a flight attendant can organize passenger behavior during both actual and experimental evacuations, without producing idiosyncratic effects or interactions that necessarily render the results of evacuation studies inapplicable to rulemaking.

- Interactions between evacuation system elements (physical, information, operator, and user) are generally linear and physically circumscribed to the area of the exit opening.

- There should be no reliance on one class of evacuation system elements (physical, information, etc.) to overcome deficiencies in another. Regulatory strategies adhere to this principle by having multiple rules related to both single and multiple evacuation factors. These include rules on exit size and passenger ratings, exit distribution, descent assisting means, emergency lighting, safety briefing cards, signs, placards, emergency procedures, and crew emergency training, to name a few.

\section{REFERENCES}

ARAC Performance Standards Working Group, Performance-Based Rulemaking for Transport Category Airplanes: A Systems Approach, Washington, DC, July 1998.

Code of Federal Regulations, Title 14, Aeronautics and Space, Vol. 1, US Govt Printing Office, Washington, DC, January 1, 2000.

Crane, CR, Human Tolerance Limit To Elevated Temperature: An Empirical Approach To The Dynamics Of Acute Thermal Collapse, Memorandum Report No. AAC-114-78-2, FAA Civil Aeromedical Institute, Oklahoma City, OK, May 1978. 
Fennell, PJ and HC Muir, The Influence Of Hatch Weight And Seating Configuration On The Operation Of A Type III Hatch, CAA Paper 93015, Civil Aviation Authority, UK (1993).

Garner, JD and JG Blethrow, Emergency Evacuation Tests Of A Crashed L-1649, Office of Aviation Medicine Report, AM 66-42, Washington, DC, August 1966.

Hasbrook, AH, JD Garner, \& CC Snow, Evacuation Pattern Analysis Of A Survivable Commercial Aircraft Crash, Office of Aviation Medicine Report, AM 62-7, Washington, DC, 1962.

Loftus, GR, A Picture Is Worth A Thousand p Values: On The Irrelevance Of Hypothesis Testing In The Microcomputer Age, Behavior Research Methods, Instruments, and Computers, 25 (2), 250-256, 1993.

McLean, GA, EA Higgins, PJ Lyne and JHB Vant, The Effects Of Wearing Passenger Protective Breathing Equipment On Evacuation Times Through Type-III and Type-IV Emergency Exits in Clear Air and Smoke, Office of Aviation Medicine Report, DOT/FAA/AM-89/12, Washington, DC, November 1989.

McLean, GA, CB Chittum, GE Funkhouser, GW Fairlie, and EW Folk, Effects of Seating Configuration And Number Of Type III Exits On Emergency Aircraft Evacuation, Office of Aviation Medicine Report, DOT/ FAA/AM92/27, Washington, DC, August 1992.

McLean, GA, MH George, CB Chittum \& GE Funkhouser, Aircraft Evacuations Through Type-III Exits I: Effects of Seat Placement At The Exit, Office of Aviation Medicine Report, DOT/FAA/AM-95/22, Washington, DC, July 1995.

McLean, GA and MH George, Aircraft Evacuations Through Type-III Exits II: Effects Of Individual Subject Differences, Office of Aviation Medicine Report, DOT/FAA/AM-95/25, Washington, DC, August 1995.

McLean, GA, CL Corbett and MH George, Passenger Management Strategies For Emergency Egress Through Airliner Overwing Exits, Presented at the Aerospace Medical Association Annual Scientific Meeting, Detroit, MI, May 1999.
McLean, GA and CL Corbett, Effects Of Individual Subject Differences On Egress In Simulated Aircraft Emergency Evacuations, Presented at the Aerospace Medical Association Annual Scientific Meeting, Houston, TX, May 2000.

Mohler, SR, JJ Swearingen, EB McFadden, \& JD Garner, Human Factors Of Emergency Evacuations, Office of Aviation Medicine Report, AM 65-7, Washington, DC, 1965.

Muir, H, The Effect On Aircraft Evacuations Of Changes To The Vertical Projections Between The Seat Rows Adjacent To The Overwing Exit From 3" to 6", 10" and 13", Cranfield University, CoA Report No. 9408, 1996.

Muir, H, C Marrison, \& A Evans, Aircraft Evacuations: The Effect Of Passenger Motivation And Cabin Configuration Adjacent To The Exit, Civil Aviation Authority UK, CAA Paper 89019, November 1989.

Muir, H, C Marrison, \& A Evans, Aircraft Evacuations: Preliminary Investigations Of The Effect Of Non-Toxic Smoke And Cabin Configuration Adjacent To The Exit, Civil Aviation Authority UK, CAA Paper 90013, 1990.

Muir, H, D Bottomley, \& J Hall, Aircraft Evacuations: Competitive Evacuations In Conditions Of Non-Toxic Smoke, Civil Aviation Authority UK, CAA Paper 92005, March 1992.

Perrow, C, Normal Accidents: Living With HighRisk Technologies, Basic Books, New York, NY, 1999.

Rasmussen, PG and CB Chittum, The Influence Of Adjacent Seating Configurations On Egress Through A Type III Emergency Exit, Office of Aviation Medicine Report, DOT/FAA/AM-89/14, Washington, DC, (1989).

Snedecor, G.W. and WG Cochran, Statistical Methods, The Iowa State University Press, Ames, Iowa, 1967.

Walpole, R.E. and RH Myers, Probability And Statistics For Engineers And Scientists, The MacMillan Company, New York, 1972. 